\title{
Corporate sustainability interactions: A game theoretical approach to sustainability actions
}

\author{
Damla Durak Uşar ${ }^{\mathrm{a}, *}$, Meltem Denizel ${ }^{\mathrm{b}}$, Mehmet Ali Soytaş ${ }^{\mathrm{c}}$ \\ a Özyeğin University Sustainability Platform, Çekmeköy Campus, Nişantepe District, Orman Street, 34794 Çekmeköy, Istanbul, Turkey \\ ${ }^{\mathrm{b}}$ Iowa State University, Ivy College of Business, Supply Chain and Information Systems Department, , Ames, IA, 50011, USA \\ c Özyeğin University, Faculty of Business Çekmeköy Campus, Nisantepe District, Orman Street, 34794, Çekmeköy, Istanbul, Turkey
}

\section{A R T I C L E I N F O}

\section{Keywords:}

Game theory

Corporate sustainability

Competition

Spillovers

Stackelberg game

\begin{abstract}
A B S T R A C T
Recent global developments lead companies to include into their strategic plans not only economic sustainability but environmental and social sustainability as well. Companies have been investing in environmental and social sustainability to meet stakeholder demand and/or regulatory demands. Considering this as a market mechanism, we view the sustainability actions of companies as interrelated strategic decisions and propose a Stackelberg game to model the effects of competition for sustainability and sustainability spillovers over the sustainability outcomes of companies. We provide equilibrium solutions for the one leader, two followers game over different intervals of competition levels and spillover rates. Using a numerical example, we observe how the sustainability investments and net benefits change as competition levels and spillover rates change and identify the competition-spillover regions, where each player invests the most and has the advantage in terms of benefit. We discuss implications for both the companies and the policy makers.
\end{abstract}

\section{Introduction}

Sustainability research has addressed different mechanisms behind firm behavior regarding their sustainability initiatives and the resulting financial outcomes from different theoretic lenses. Proponents of the Stakeholder Theory (Donaldson and Preston, 1995; Berman et al., 1999) suggest that sustainability initiatives such as engaging in product differentiation in terms of environment friendly product characteristic, signaling corporate citizenship, or communication of commitment to sustainability to consumers will lead to increased reputation and market share, which in turn will enhance financial performance (Preston and O'Bannon, 1997; Hall and Wagner, 2012).

From a different perspective, the Resource Based View (RBV) of the firm (Wernerfelt, 1984) suggests that sustainability initiatives lead to cost advantages since they improve processes and practices of a company (Cristmann, 2000; Darnall et al., 2008; Schoenherr and Talluri, 2013). Examples for sustainability initiatives, which lead to a decrease in operation costs, are product design for environment, responsible sourcing and conservation of natural resources, energy consumption and greenhouse gas emissions reduction, pollution reduction, waste reduction, inventory management and warehousing, packaging and mode of transportation, and extended producer responsibility (Hitchcock and Willard, 2009). There is plenty of empirical evidence on the positive impact of sustainability initiatives on operation costs. Positive and significant impact of pollution prevention and waste reduction on cost (Schoenherr, 2012), positive impact of process innovation, which converts a waste stream into a useful and saleable by-product, on the original products' costs (Lee, 2012), cost advantages of intermodal transportation, which incorporate the environmental impact of transportation and inventory (Battini et al., 2014), interrelationships between capacity utilization, customer satisfaction, energy consumption reduction, and costs in a product recovery setting (Mangala et al., 2013) are examples to name a few.

As stated by Mendoza and Clemen (2013), sustainability initiatives such as recycling or reducing energy consumption (which lead to cost reduction) may generate more direct net benefit compared to corporate social responsibility initiatives, which enhance the social infrastructure. While the latter increases the reputation of the company, improves consumer goodwill, and generates financial performance through the mechanisms of the Stakeholder Theory, the former improves financial performance through the mechanisms of RBV and Stakeholder Theory. If sustainability initiatives such as recycling or energy consumption reduction are communicated to the stakeholders, reputation should improve as well. Thus, albeit the different motivations such as moral or value-based motivations, legitimacy concerns, managerial-agency-based motivations, institutional motivations,

\footnotetext{
* Corresponding author.

E-mail addresses: damla.usar@ozyegin.edu.tr (D.D. Uşar), mdenizel@iastate.edu (M. Denizel), mehmet.soytas@ozyegin.edu.tr (M.A. Soytaş).
} 
responsiveness to activists and/or strategic motivations (Carroll et al., 2016), adopting sustainability initiatives generate directly or indirectly favorable financial outcomes. Moreover, stakeholder engagement and transparency around sustainability performance lead to a better access to finance and, firms with better sustainability performance face, on average, lower capital constraints (Cheng et al., 2014). Investors believe that solid sustainability performance of a company leads to improved revenue performance, reduced risk, and lower cost of capital (Unruh et al., 2016).

Academic research provides evidence supporting that companies investing in sustainability especially in environmental sustainability gain competitive advantage (Golicic and Smith, 2013; Yadav et al., 2017). Eccles et al. (2014) report that high sustainability companies outperform the low sustainability ones in terms of both stock market and accounting measures. Further evidence comes from Unruh et al. (2016); organizations that have made a sustainability related business model change are twice likely to report profit from sustainability than those that haven't. Furthermore, extensive literature review studies (e.g. Peloza, 2009; Margolis et al., 2009; Grewatsch and Kleindienst, 2017) concur that empirical evidence predominantly supports the positive link. Since both empirical evidence as well as anecdotal evidence assert that sustainability initiatives lead to economic benefits, research attention has recently begun to shift from whether it pays to be good to when and under what circumstances (Orlitzky et al., 2011; Grewatsch and Kleindienst, 2017).

We aim to identify when and under what circumstances companies benefit from sustainability adoption. However, both conceptually and empirically, the literature views sustainability adoption mostly from a micro perspective, whereas companies make these decisions in a macro business environment. Hofer et al. (2012) also point out to the paucity of research incorporating the effect of competition on implementation of environmental management (EM) activities. They advocate that EM has strategic and competitive importance and present empirical evidence that firms compete in terms of EM activities. Similarly, we advocate that sustainability actions of a company impact its marketplace and vice versa. Our purpose is to shed some light on how strategic interactions between companies affect their sustainability actions and incorporate the effect of competition into our analysis.

We propose a game theoretical model for sustainability interactions. We introduce the concept of "sustainability market," which is the competitive environment that can award or penalize firms according to whether they invest in sustainability or not. We refer to the situation that a firm undertakes significant amount of sustainability related activities as the single firm's entrance in to the sustainability market. Stakeholders can observe how and when firms incorporate sustainability in their products, processes, and strategies. We argue that entry into the sustainability market by investing in sustainable practices is valued by the stakeholders and potentially increase the financial returns (if the return to sustainability is positive).

Depending on the nature of the sustainability initiatives undertaken by the firm, stakeholder payment to sustainability would occur in various forms such as: i) increased willingness to pay a price premium, increase in favorable purchase decisions, improved brand value through environmentally friendly product mixes and corporate social responsibility, reduction in production costs through operational efficiencies and improved workplace productivity ii) increase the firm valuation in the eyes of the investor iii) easy access to financing and iv) tax advantage. The firm's collection of the returns from the sustainability efforts, however, depends on whether the competitor/fellow firms also perform same/similar or different sustainable actions.

It is likely that different sustainability actions will have different effects on the overall competition in the market (Galbreth and Ghosh, 2013). The decomposition of competition into negative effect and positive effect (spillover) provide better understanding how strategic interactions influence the sustainability decisions of companies.

\section{i) negative effect of competition}

If the entry decision of company $\mathrm{j}$ changes the expectation of stakeholders from company $i$ (for instance for a sustainable version of the product or a lower price) then the net benefit of company $i$ will decrease. Company i either does not change her product offering regarding sustainability or price and loses demand and market share or decides to adapt to the shifting expectations of stakeholders and incurs new costs. The negative effect of competition in the sustainability market is in line with the conventional effect of competition on market entry which has been established by industrial organization literature for a long time. The industrial organization literature has established that the stakeholder valuation for a particular action decreases as more companies take similar actions. Companies implement sustainability actions to differentiate themselves from their competitors. However, as more companies engage in sustainability activities, the competitive advantage provided by the sustainability initiative decreases.

\section{ii) positive effect of competition-spillover}

It is likely that different sustainability actions will have different effects on the overall competition in the market (Galbreth and Ghosh, 2013). If the sustainability efforts of a company lead to an improved stakeholder perception of the whole industry, there may be sustainability spillovers and other companies may free ride the sustainability efforts of the leader company. For instance, a public education activity on dental health undertaken by a specific producer of toothpaste may lead to an increase in the overall toothpaste sales. Similarly, if a company imitates the competitors' sustainability actions, the implementation cost for that company will be lower compared to the competitors' costs. The follower benefits from the spillovers without bearing the full cost of the investments and again that company free rides the sustainability efforts of her competitors.

To address these dynamics, we develop a sequential single leadermultiple follower game and model the effect of competition level and spillover rate on the sustainability outcomes and net benefits of the leader and followers. We provide the analytical equilibrium solutions and examine how the leader's sustainability efforts affect the followers' sustainability activities for all possible values competition level and spillover rate can take in their respective domains. We demonstrate the conditions, when the leader attains the first mover advantage and the followers attain the late mover advantage.

The model results suggest that when negative effect of competition is greater than the positive effect of spillovers only the leader invests in sustainability and the first mover receives the whole stakeholder payment in the sustainability market, since her competitors have not yet invested in sustainability. In this case, the accumulation of know-how and experience of the leader may make it hard for the rivals to replicate her sustainability investments immediately. However, in the presence of substantial sustainability spillovers, the leader's position is challenged by new comers. As more companies invest in sustainability, in order to maintain competitive advantage, the leader needs to continue to innovate further, otherwise she will lose her competitive advantage. Nevertheless, when the positive effect of spillovers is less than the negative effect of competition the leader and both followers invest in sustainability and the second follower benefits more than the leader. The late adopter has an advantage, since she benefits from cumulative spillovers-increased net benefits due to market expansion caused by improved stakeholder perception of the whole industry and decreased implementation costs. The intermediate adopter fails to follow a clear strategy and cannot gain advantage over her competitors.

By modeling strategic sustainability interactions in an oligopolistic market, we contribute to the ongoing debate about the impact of industry structure on sustainability and financial outcomes generated by sustainability. Furthermore, we show the effect of competition and spillovers on the overall sustainability outcome of the market. The 
results regarding the total market sustainability outcome provide an important basis for policy makers in design and reinforcement of regulations regarding sustainability.

The rest of the paper proceeds as follows: Section 2 presents brief literature review on competitive interactions between companies regarding their sustainability actions such as introduction of a sustainable product, reduction of pollution, implementation of sustainable operations practices or closing the supply chain loop. Section 3 develops the theoretical basis for analyzing the influence of competition on sustainability actions and financial outcomes, introduces the game theoretic model which allows the sustainability actions to be interdependent among the firms and provides the analytical solutions. Section 4 describes and discusses the results and their implications by means of illustrative examples. Section 5 concludes with future research opportunities.

\section{Literature}

Game theory is suitable for analyzing situations in which the decisions of companies affect each company's benefit. We distinguish between studies where cooperative and non-cooperative game players are considered. The cooperative game-theoretic models consider the fair distribution of benefits and costs among stakeholders such as the government, the local authorities, the companies, and the community. In multi-stakeholder cooperative situations, such as life cycle management, water resource sharing or waste management, the outcome is affected by the decisions made by every player (Karmperis et al., 2013). Waste management decisions such as selecting a new landfill site (Cheng et al., 2003), division of waste management costs (Moretti, 2004), waste disposal (Jørgensen, 2010), selection of sustainable waste treatment options (Soltani et al., 2016) and water resource management decisions such as sanitation (Leoneti and Pires, 2017) have been modeled as cooperative games.

Non-cooperative game players make decisions independently from each other. According to Ruf et al. (2001) companies have two choices to meet the stakeholder demand for increasing corporate sustainability performance, namely, compliance or active support. They assert that if a company is proactive and changes its business processes in order to become more sustainable, then it will gain competitive advantage over its competitors who are being reactive towards stakeholder demand. Static games such as price or quantity competitions, new product introduction, and competition in remanufacturing can be modeled as noncooperative games.

Moraga-González and Padrón-Fumero (2002) consider a duopoly market with product differentiation, where consumers are concerned with the emissions. Rodriguez-Ibeas (2007) studies a standard vertical product differentiation model, where firms simultaneously choose their prices. He assumes that the polluting firm has cost advantage over the non-polluting firm. If the consumers are not sensitive to the environment, due to her cost advantage, the polluting firm decreases her price to capture the whole market. The polluting firm's output decreases with increasing environmental awareness. However, until a critical level of environmental awareness is reached the polluting firm still benefits due to the cost advantage. Kopel (2009) considers the effect of spillovers in a duopoly setting with product differentiation and model a Cournot game, where leader and follower compete for demanded quantities which depend on both prices and the sustainability activities of both players.

Orsdemir et al. (2014) study a quantity competition between an Original Equipment Manufacturer (OEM) and independent remanufacturer (IR), where the interdependence is twofold. (i) Remanufactured product's cost and quality level depend on the new product's quality level. (ii) Similarly, according to Majumder and Groenevelt (2001) the end-of-life products available for IR are limited to the new products supplied by the OEM. They investigate the impact of remanufacturing and quality choice on consumer surplus and social surplus and find that IR's entry decreases the consumer surplus and social surplus. Moreover, from an environmental perspective it is more favorable that the OEM remanufactures.

Sabbaghia et al. (2016) model the interactions between consumers and OEM, which remanufactures returned electrical and electronic equipment. Since returned goods are inputs to the remanufacturing operation, the OEM has to control the rate and timing of returns. In order to do so, the OEM rewards consumers for participating in the take back program. In the proposed game-theoretic model the consumers decide on their optimal storage times while OEM decides on the optimal value of the incentive reward. Similarly, Esenduran et al. (2017) study the effect of take-back regulations on the OEM and IR decisions, consumer surplus and the OEM's profit. They find that although stringent collection regulations are in favor of the OEM, they lead to decreased remanufacturing.

Sequential order of moves such as incumbency, sequential entry, R\& D races, can be captured by the Stackelberg model (Huck et al., 2001). Sustainability decisions such as disclosure, outsourcing, new product entry, supply chain coordination, price and quantity competition in a remanufacturing setting are modeled as repeated games. In disclosure models, a firm decides to disclose information on its sustainability activities and the opponent decides to strike or not. In the sequential model proposed by Li et al. (1997) the market reacts to both disclosure and strike decisions. Li et al. (1997) report that the environmental performance of a company decreases as the disclosure level increases. Sengupta (2015) considers a game, where companies signal their environmental performance. In accordance to the finding of $\mathrm{Li}$ et al. (1997) they observe that mandatory disclosure of environmental performance decreases investment in clean technologies. Mendoza and Clemen (2013) formulate the outsourcing decision as a Stackelberg game, where in the first stage the sustainability buyer decides on the level of economic or technical support to incentivize sellers' efforts and in the second stage two sustainability sellers decide on their effort levels. Plambeck and Wang (2009) formulate and compare a monopoly model and a duopoly model to study the effects of various waste regulations on the new product introduction process, quantity of e-waste, social welfare, consumer surplus, and manufacturer profit.

Conrad (2005) models a spatial duopoly market, where equilibrium prices and market shares are affected by consumers' awareness of environment. At the first stage, companies choose product characteristics and at the second stage companies decide on the price. Liu et al. (2012) propose a dynamic two-stage game of production and retail competition that incorporates consumer environmental awareness. In the first stage, the manufacturers decide on the environmental improvement and wholesale price. In the second stage the retailers set the price of the product. They study the impact of consumers' environmental awareness on price competition under the assumptions that production of ecofriendly products is costlier and consumers are willing to pay higher prices for more eco-friendly products. Xu et al. (2017) analyze a twoechelon supply chain consisting of one supplier and one manufacturer and model their optimal pricing and carbon emissions intensity decisions as a Stackelberg game. They incorporate the effect of environmental awareness and technological spillovers into their analysis and compare centralized and decentralized supply chains.

Majumder and Groenevelt (2001) model a two-stage duopoly game in a remanufacturing setting, where players compete for resource allocation as well as price and quantity. In the first period, the OEM produces and sells new items. Only a fraction of these items is returned and available for the OEM and the IR to remanufacture in the second period. Hence, in the second period each player's competitive response depends on this state variable. They utilize a demand function such that the quantity sold by each player depends on both his own price and the competitor's price. Jacobs and Subramanian (2012) study the effect of regulations on the amount of collected and recycled end of life cycle products and the associated profits in integrated and decentralized supply chains. They propose a two stage model, where the supplier sets 
the wholesale price and recycling rate and the manufacturer chooses the total quantity as a best response. They show that sharing the responsibility for product recovery between the stages can improve total supply chain profit.

Besley and Ghatak (2007) study a setting where companies compete in a Bertrand-like fashion. The company decides to seek profit maximization or to be socially responsible, whereas the consumer decides which firm to purchase from or whether not to buy the good at all. Although the authors analyze product market, they assert that the basic idea applies to labor markets (labor donation), or capital markets (ethical investment) and conclude that more responsible firms earn higher profits, as a reputational premium to support good behavior.

Kopel et al. (2014) introduce a Stackelberg game, where competitors make a strategic decision on whether they are profit maximizing companies or socially responsible companies in the first stage and in the second stage a quantity competition takes place. They introduce the consumer surplus into the objective function in order to represent socially responsible companies. In the second stage they introduce different reservation prices for profit maximizing and socially responsible companies to capture the vertical product differentiation. If both companies have the same costs, the socially responsible company attains more benefits compared to the profit maximizing company. Manasakis et al. (2014) consider a Cournot game, where companies signal their corporate social responsibility performance by hiring a manager who is publicly known to be socially responsible. In turn, consumers increase their willingness to pay for this firm's product which then obtains a competitive advantage in the market and increases its profits. Similar to Kopel et al. (2014), Lambertini and Tampieri (2015) account for consumer surplus when formulating the objective function and study a Cournot oligopoly with pollution, where companies decide on their sustainability strategy. They find that the sustainable firm obtains higher profits than its profit-seeking competitors, and generates a higher level of social welfare.

There is a wide range of studies modeling strategic interactions regarding sustainability decisions. However, the research questions addressed even in the studies that relate most to this study as discussed above, differ substantially. They model sustainability interactions, where companies decide to produce a more sustainable version of a homogeneous product and compete in quantities or prices, which are decisions more on the operational and tactical level. Whereas sustainability at firm level covers wide range of topics from environmentally friendly product mix and lean sustainable operations to corporate social responsibility and employee workplace satisfaction. This broader definition of sustainability from our perspective is a part of the firm's strategy. Some of these areas might but in general most would not be directly tied to the operation/production level of the firm per se. Thus we do not link the sustainable investment level of a firm directly to the production level of the firm and aim to propose a model sufficiently general, which can cover the wide range of topics associated with sustainability.

We model sustainability interactions, where there is a demand for sustainability from various stakeholders and a payoff from being sustainable. The companies compete for stakeholder payments and decide on their sustainability levels, which maximize their net benefit by taking the opponents actions into account. As a result, we propose a game theoretical model to describe the effects of competition and spillovers on the sustainability initiatives and net benefits generated by these sustainability initiatives. We distinguish between the negative and positive effect of competition.

In classical entry models the entry of company $\mathrm{j}$ into a market decreases the net benefit of the company $i$, since the companies will compete for the market shares. As more companies enter the market, net benefits decrease. Similarly, as more companies invest into sustainability-enter the sustainability market-a decrease in net benefits may be expected. All competitors -the leader as well as the followersare influenced by the negative effect of competition. Thus, the follower's sustainability choice has negative effect on the leader and predecessor followers' return of sustainability.

Distinctly, competition in sustainability influences the net benefits not only negatively, but also positively in terms of spillovers. Spillovers may occur twofold. $i$ ) If the sustainability efforts of company $j$ lead to an improved stakeholder perception of the whole industry, the whole market may expand and company $i$ receive increased net benefit as well. ii) If company $j$ invests in sustainability initiatives earlier compared to company $i$, company $i$ can imitate these sustainability initiatives and increased net benefit due to decreased implementation costs. Both spillovers have sequential nature within an echelon: The sustainability action of the leader/predecessor follower has to occur first, so that the stakeholder perception of industry improves leading to market expansion. Similarly, sustainability action of the leader/predecessor follower has to occur first, so that the followers can imitate the action leading to lower implementation costs. We assume that spillovers occur from leader to followers and from predecessor follower to successor followers. We propose a sequential model in an oligopoly setting, provide analytical solutions and quantify the effect of competition and spillovers using illustrative examples for better visual representation.

\section{The game theoretical model}

In this section, we conceptualize sustainability actions of companies as strategic interactions and model the competition among companies in an oligopolistic market. The goal of the focal company is to maximize the net benefit obtained from sustainability considering the sustainability actions of her competitors. We start our analysis by constructing a net benefit function. According to the RBV companies obtain benefit from investing in sustainability. The supply-side perspective points out that companies have to allocate resources in order to satisfy the demand for sustainability. Thus, we can modify the microeconomic concepts of production and cost functions to include sustainability-related inputs, which incur costs and outputs, which generate benefit (McWilliams et al., 2001). We provide the notation used in Table 1.

The companies' objective is to choose the level of sustainability $w_{i} \geq$ 0 that maximizes their net benefit function subject to competitors' sustainability levels. The company $i$ decides on the best action by anticipating the actions of its competitors.

The net benefit function of the focal company $i$ is calculated as:

$\Pi_{i}^{\text {sus }}\left(w_{i}, \boldsymbol{w}_{N / i}\right)=\mathrm{r}_{i}^{\text {sus }}\left(w_{i}, \boldsymbol{w}_{N / i}\right)-\mathrm{c}_{i}^{\text {sus }}\left(w_{i}, \boldsymbol{w}_{N / i}\right)$

On the one hand, companies may decide to invest in sustainability voluntarily. These companies undertake sustainability initiatives, if their expected benefits exceed the expected costs of sustainability, since they are assumed to be rational decision makers. Thus, company $i$ undertakes sustainability initiatives voluntarily, if the net benefits $\Pi_{i}^{s u s}\left(w_{i}, \boldsymbol{w}_{N / i}\right)>0$. On the other hand, if companies are coerced into investing in sustainability, either they comply with the new regulations or they face fines for not adopting. For these companies the sustainability investment decisions boil down to whether their expected net benefits exceed the fines for not adopting. Thus, company $i$ complies with regulations and undertakes sustainability initiatives, if the net benefits $\Pi_{i}^{\text {sus }}\left(w_{i}, \boldsymbol{w}_{N / i}\right)>f_{i}$. We model sustainability interactions of companies that undertake sustainability initiatives voluntarily. However, the model applies also to companies that are coerced into investing in sustainability. Simply the fixed amount of fines $f_{i}$ should be incorporated into the analysis as well.

To obtain closed-form solutions and discuss the implication of different parameters, we use specific functional forms. On the one hand Piga (2002) predicts that in oligopolistic markets, in equilibrium, firms which supply sustainable goods reap 'abnormal' profits. On the other hand, McWilliams et al. (2006) claim that the costs of sustainability balance out the benefits generated from sustainability and advocate that for both oligopoly and monopolistic competition in equilibrium, 
Table 1

Notation.

\begin{tabular}{|c|c|}
\hline $\mathrm{i}$ & company index, $\mathrm{i}=1, \ldots \ldots, \mathrm{N}$ \\
\hline$w_{i}$ & level of sustainability initiatives of company $i, w_{i} \geq 0$ \\
\hline $\boldsymbol{w}_{N / i}$ & vector for all players' level of sustainability initiatives, excluding company i. \\
\hline $\mathrm{r}_{i}^{\text {sus }}\left(w_{i}, \boldsymbol{w}_{N / i}\right)$ & benefit of undertaking sustainability at level $w_{i}$ given competitors' sustainability levels \\
\hline$c_{i}^{\text {sus }}\left(w_{i}, \boldsymbol{w}_{N / i}\right)$ & implementation cost of undertaking sustainability at level $w_{i}$ given competitors' sustainability levels \\
\hline$f_{i}$ & fixed amount of fines, if company i does not comply with the regulations \\
\hline$\Pi_{i}^{\text {sus }}\left(w_{i}, \boldsymbol{w}_{N / i}\right)$ & Net benefit of undertaking sustainability at level $w_{i}$ given competitors' sustainability levels \\
\hline$w_{L}:$ & level of sustainability initiatives of the leader \\
\hline$w_{F_{i}}$ & level of sustainability initiatives of follower i \\
\hline$p_{L}\left(w_{L}, w_{F_{i}}\right)$ & stakeholder payments for the leader for sustainability level $w_{L}$ \\
\hline$p_{w_{F_{i}}}\left(w_{L}, w_{F_{i}}\right)$ & stakeholder payments for follower i for sustainability level $w_{F_{i}}$ \\
\hline a & initial willingness of the stakeholder to pay for sustainability initiatives, $a>0$ \\
\hline $\mathrm{b}$ & rate at which the willingness to pay decreases as sustainability initiatives increase, $b>0$ \\
\hline $\mathrm{d}$ & marginal cost for sustainability investment for both the leader and the followers, $d>0$ \\
\hline$\gamma_{i}$ & sustainability spill overs for follower $\mathrm{i}, \gamma_{i} \in[0,1]$ \\
\hline$\gamma$ & sustainability spill overs at constant rate for all followers, $\gamma \in[0,1]$ \\
\hline$\theta:$ & level of competition, $\theta \in[0,1]$ \\
\hline$R_{F_{i}}\left(\sum_{j \neq i}^{N-1} w_{F_{j}} \mid w_{L}\right)$ & follower i' s reaction to arbitrary sustainability levels by other followers subject to the leaders sustainability level $w_{L}$ \\
\hline $\mathrm{w}_{i}^{*}:$ & player i's optimal investments given arbitrary sustainability levels by other players \\
\hline$r_{L}^{\text {sus }}\left(w_{L}, w_{F_{i}}\right):$ & benefit of the leader from undertaking sustainability initiatives \\
\hline$r_{F_{i}}^{\text {sus }}\left(w_{L}, w_{F_{i}}\right):$ & benefit of the follower from undertaking sustainability initiatives \\
\hline$c_{L}^{\text {sus }}\left(w_{L}, w_{F_{i}}\right)$ & cost of the leader from undertaking sustainability initiatives \\
\hline$c_{F_{i}}^{\text {sus }}\left(w_{L}, w_{F_{i}}\right)$ & cost of follower i from undertaking sustainability initiatives \\
\hline$\Pi_{L}^{\text {sus }}\left(w_{L} \mid p_{L}\left(w_{L}, w_{F_{i}}\right)\right)$ & net benefit of the leader from undertaking sustainability initiatives \\
\hline$\Pi_{F_{i}}^{\text {sus }}\left(w_{F_{i}} \mid p_{F_{i}}\left(w_{L}, w_{F_{i}}\right)\right):$ & net benefit of the follower from undertaking sustainability initiatives \\
\hline
\end{tabular}

the net benefits of firms that implement sustainability is the same as the net benefits of the firms that do not implement sustainability. Based on the evidence provided by empirical sustainability research, we suppose that sustainability generates abnormal profits and expect that the increase in net benefits will deteriorate as the firm increases its level of sustainability. Thus, we assume that the net benefit function is an increasing concave function in sustainability efforts.

The source of the benefits can be twofold. (i) Based on the Stakeholder Theory, when a company invests in sustainability and these efforts are visible by the stakeholders, then the company is perceived as sustainable and the stakeholders provide incentives such as increased demand, willingness to pay a price premium, tax benefit or better financing opportunities. (ii) Based on the RBV, sustainability initiatives lead to process improvement and increase in employee productivity, which in return lead to reduction in operating costs.

However, both these benefits are expected to diminish. As more companies become sustainable, stakeholders no longer differentiate between companies based on sustainability and the stakeholder incentives decrease. Similarly, the reduction in operating costs is expected to go down as firms increase their level of sustainability. In this model, we do not distinguish between benefits due to stakeholder incentives and cost reduction, and assume that they both diminish as sustainability efforts increase. Therefore, we assume that the benefit function $\mathrm{r}_{i}^{\text {sus }}\left(w_{i}, \boldsymbol{w}_{N / i}\right)$ is an increasing concave function in $w_{i}$, and the marginal increase in benefits will deteriorate as the firm increases its level of sustainability. This assumption is in line with previous literature as well. There are plenty of studies utilizing a concave functional form to model the return to various sustainability decisions.

Moraga-González and Padrón-Fumero (2002) model the introduction of a more sustainable version of a homogeneous product and subsequent price competition and assume that the technology for the sustainable variant exhibits decreasing returns. Plambeck and Wang (2009) study effect of regulations on the new product introduction process, quantity of collected and recycled end of life cycle products and waste and assume that the marginal return on time and expenditure is decreasing. Jacobs and Subramanian (2012) evaluate different policy decisions and propose that the profit of the integrated supply chain under no regulation is jointly concave in the total produced quantity and recycling rates. Sabbaghia et al. (2016) study decisions on the rate and timing of end of life cycle product returns and define the utility function of OEM as the difference between the profit obtained from remanufactured products and the incentive values paid to the consumers for returning the end-of life cycle goods. Their model results suggest that the OEM utility is concave in incentives.

In all the aforementioned studies, the marginal return on sustainability efforts (e.g. technology for the sustainable variant, time and expenditure to collect end of life cycle products, recycling rates and incentive values paid to the consumers for returning the end-of life cycle goods) is decreasing. Mendoza and Clemen (2013) model decision on outsourcing of recovery activities and assume that the profit function is an increasing and concave function. They elaborate on the logic behind their assumption; in order to achieve a maximum level of benefit companies invest in sustainability projects with a higher direct benefit per unit of effort first and remark that this assumption is consistent with widely used approaches such as the McKinsey Abatement Curve (Enkvist et al., 2007). Thus, the assumption of the net benefit profit functions being strictly concave with respect to the sustainability efforts is standard assumption, which we adopt as well.

The effect of competition on the implementation costs of company $i$ is not straightforward as the effect of competition on its benefits. $\mathrm{c}_{i}^{\text {sus }}\left(w_{i}, \boldsymbol{w}_{N / i}\right)$ is not only affected by the actions of the focal company but also by the actions of the competitors. For example, if a company simply imitates its competitors' sustainability initiatives, the implementation cost for that company may be lower compared to the competitors' costs. We expect that the marginal cost of implementation will increase as the level of sustainability initiatives increase. Thus, the implementation costs of sustainability initiatives $c_{i}^{\text {sus }}\left(w_{i}, \boldsymbol{w}_{N / i}\right)$ are assumed to be increasing and convex in $w_{i}$, when learning effects ${ }^{1}$ are neglected.

Liu et al. (2012) point out that it is well-known that environmental

\footnotetext{
${ }^{1}$ The learning effects are based on the concept that, as a task is performed repetitively, the time required to perform the task decreases. Similarly, the incremental cost of sustainability implementation decreases.
} 


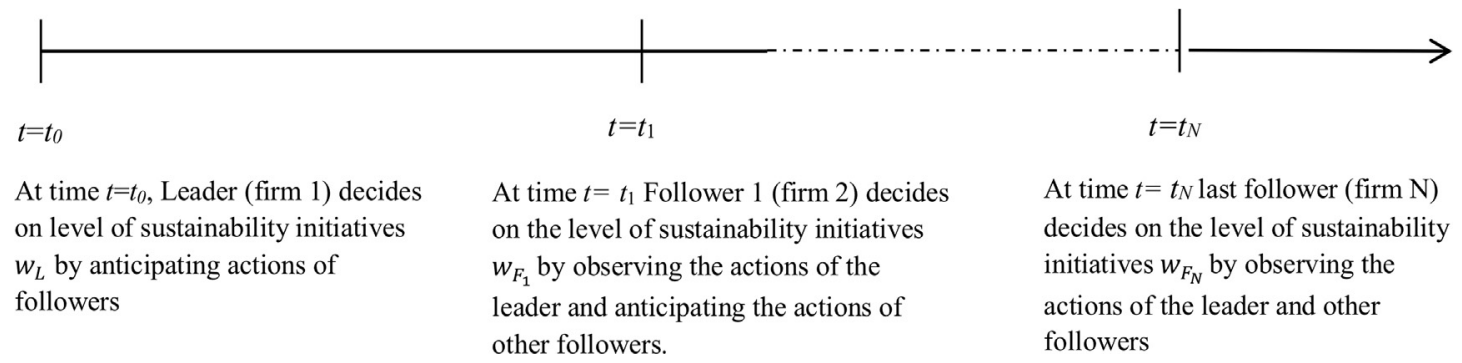

Fig. 1. Time line for Sequential Single Leader- Multiple Follower Game.

improvement has an increasing marginal cost. Each additional increment of pollution prevention is more difficult, and hence costlier to achieve, which is also associated with the phenomenon of diminishing returns.

\subsection{Sequential Single Leader-Multiple Follower Game with spillovers}

According to Ferrier et al. (1999) there is a time lag between the observation of a firm's sustainability action and the response of its competitor. In his Harvard Business Review article Unruh [2010] presents anecdotal evidence of companies investing in sustainability because industry peers already invested in sustainability (Unruh, 2010). Furthermore, Hofer et al. (2012) suggest that sustainability activities are not synchronous and the competitive moves of the focal company and her competitors should be analyzed over time. Matisoff 2015 claims that the sustainability behavior of industry leaders changes the sustainability behavior of followers for the better and draws attention to the evidence supporting dissemination of best practices across the industry in the sustainability literature.

Drawing on the literature and our practical observations we anticipate, that companies make sustainability decisions based on the actions of fellow companies and in a sequential manner. Thus, we prefer to model sustainability interactions as Stackelberg game instead of a simultaneous game. However, the effect of competition remains ambiguous, unless opposing effects of competition are decomposed. On the one hand the stakeholder valuation for a sustainability initiative decreases as more companies take similar actions. On the other hand, as pioneer companies invest in sustainability initiatives they transform the market, so that the marginal return of sustainability is higher for followers compared to pioneers.

The variable $w_{i}$ may indicate that company $i$ invested a certain amount in making its products be easily disassembled for remanufacturing, or in process improvement in terms of energy, water or virgin material efficiency, which also leads to cost efficiency, or company $i$ invested a certain amount in a corporate social responsibility project and $w_{i}$ may also indicate the effort the company $i$ puts to comply with international human rights laws, so that it is selected as a supplier to international companies. Will the competitors benefit from the sustainability actions of the leading firm through an already improved customer perception of the industry or will they undertake similar initiatives themselves may be at a lower cost? How will this affect the leader and other competitors?

In the first stage, the leader decides on her sustainability level by anticipating her competitors' sustainability levels. In the subsequent stages the followers observe the leader's and their predecessor followers' sustainability investments and decide on their optimum sustainability level. This timing of the game allows us to make assumptions regarding the direction of the spillovers. We assume that spillovers occur from leader to followers and from predecessor follower to successor follower. In our model, the sustainability activities of the followers decrease the leader's return generated by sustainability investments, whereas the effect of the sustainability activities of the leader and the predecessor followers on the follower's return depends on the relation between spillovers and level of competition. In our model, we consider the time in the following manner:

We consider $\mathrm{N}$ firms with identical constant implementation costs $\mathrm{d}$. They make sequential choices of actions; firm 1 first, firm $\mathrm{N}$ last. In the first stage of the game, the leader (firm 1 ) chooses $w_{L}$ by anticipating the cumulative response of all followers. In the second stage, the follower 1 (firm 2) observes $w_{L}$ and decides on her level of sustainability investments, $w_{F_{1}}$ anticipating the opponents' sustainability investment $w_{F_{j}}, j=3, \ldots, N$. In the $\mathrm{N}^{\text {th }}$ stage, the last follower (firm N) observes $w_{L}$ and the cumulative sustainability investments of the opponents $\sum_{j=2}^{N-1} w_{F_{j}}$ and decides on her sustainability investments, $w_{F_{N}}$.

An alternative model, where in the first stage of the game the leader decides on her sustainability investments $w_{L}$ by anticipating the cumulative response of all followers, and in the second stage followers decide on their sustainability investments $w_{F_{j}}$ simultaneously, may also be considered. However, this model is trivial, since the cumulative response of the followers will be equal to the response of the follower calculated in the sequential duopoly model as per, $\sum_{j=2}^{N} w_{F_{j}}=w_{F}$. Moreover, the sustainability investments of the leader in an oligopolistic market would be equal to the sustainability investments of the leader in a duopolistic market. On the one hand, if all followers are affected from the spillovers equally, then the sustainability investments of the followers will be equal to each other, as per $w_{F_{j}}=\frac{w_{F}}{N-1}, j=2, \ldots, N$. On the other hand, if the followers are affected differently from the spillovers due to their company characteristics, their sustainability investments should be proportional to their spillover rates.

Henceforth, we will proceed with the model presented in Fig. 1.

In the classical game theoretical models, the level of competition is derived by the market shares of the companies. The corporate sustainability interactions model in this study, we use the following assumptions:

i) Stakeholders' demand is for sustainability, and companies supply for this demand. Thus, sustainability level of a company is the supply of that company to meet the demand for sustainability and should be considered like "amount of supply" for the demanded goods or services in the classical sense.

ii) Competition is not for the market share for the products or services of the companies offer, but to meet the demand for sustainability. One can argue that competition among companies for sustainability is not entirely independent of competition among companies for their product and/or service offerings due to the nature of sustainability. Nonetheless, our sustainability construct can be considered as a homogeneous "good" supplied by the companies. Due to the homogeneous goods assumption, the effect of competition is perceived by both the leader and followers and is constant among all players.

iii) We expect that the spillover effects from leader to followers will decrease over time, while the spillovers from predecessor to successor followers will increase.

iv) We assume that the rate of decrease in spillover effects from leader to followers and the rate of increase in spillover from predecessor 
followers to successor followers are at the same degree, and the cumulative spillover for arbitrary follower $j$ does not change.

To clarify assumptions iii and iv, assume sustainability spillovers occur only from leader to followers. In that case, follower 1 is expected to be benefitting more from spillovers compared to successor followers. The spillovers are expected to diminish over time. Thus $\gamma_{1}>\gamma_{2}>\ldots>\gamma_{N-1}>\gamma_{N} \geq 0$, and the assumption of spillovers occurring only from leader to followers becomes unrealistic. Spillovers $\gamma_{L j}$ occur from leader to follower $j$ and spillovers $\gamma_{i j}$ may occur among followers for $i<j$. For example, the cumulative spillover for follower $j$ would be the summation of the spillover effect from the leader, $\gamma_{L j}$ and the spillover effects from all the predecessors to $F_{j}$. Thus, total spillover for $F_{j}$ is denoted as $\gamma_{j}=\gamma_{L j}+\sum_{i=2}^{j-1} \gamma_{i j}$. It is reasonable to expect that the spillover effects from leader to followers will decrease over time. The spillovers from predecessor to successor followers, however, should increase as more followers join the market. Late adopters benefit more from spillovers occurring from predecessor followers compared to early adopters, since inter-follower spillovers accumulate.

\subsection{Sequential single leader-multiple follower game with leader-follower-} follower spillovers at a constant rate

As explained in the previous section, the sustainability leader and the followers compete for the sustainability demand. Since stakeholder's reward the companies for their sustainability efforts, companies aim to maximize their net benefits by choosing the optimum sustainability level with respect to their competitors' sustainability actions. Thus, our model resembles a quantity competition, which is widely studied in the IO literature. We refer to the reward received from sustainability investments as stakeholder payments, which correspond to the price in the classical Stackelberg model. As the number of players investing in sustainability increases, sustainability payments are expected to decrease. We formulate the stakeholder payments of the leader, follower 1 and, follower 2 as:

$p_{L}\left(w_{L}, w_{F_{1}}, w_{F_{2}}\right)=a-b\left(w_{L}+\theta\left(w_{F_{1}}+w_{F_{2}}\right)\right)$

$p_{F_{1}}\left(w_{L}, w_{F_{1}}, w_{F_{2}}\right)=a-b\left(w_{F_{1}}+(\theta-\gamma) w_{L}+\theta w_{F_{2}}\right)$

$p_{F_{2}}\left(w_{L}, w_{F_{1}}, w_{F_{2}}\right)=a-b\left(w_{F_{2}}+(\theta-\gamma)\left(w_{F_{1}}+w_{L}\right)\right)$

An increase in the competition level affects stakeholder payments of the leader and follower negatively. We assume that the spillovers occur from leader to followers and from predecessor follower to successor followers. If sustainability investments of the leader are successful, the follower may free ride the leader's sustainability efforts. Either the stakeholder perception of the whole industry shifts due to the efforts of the leader and the follower benefits from increased stakeholder payment or the follower imitates the leader's sustainability actions and benefits from the spillovers without bearing the full investment costs. For the sake of simplicity, we assume that the marginal cost for sustainability investments are constant for both the sustainability leader and the follower and denote it by $d$. We do not distinguish between the nature of spillovers (increased stakeholder payment or decrease in sustainability investment costs) and incorporate the twofold influence of spillovers as a positive effect on followers' benefits; an increase in sustainability spillovers increases the followers' stakeholder payments. The benefit from sustainability initiatives is calculated as

$r_{L}^{\text {sus }}\left(w_{L}, w_{F_{1}}, w_{F_{2}}\right)=p\left(w_{L}, w_{F_{1}}, w_{F_{2}}\right) w_{L}$

$r_{F_{1}}^{\text {sus }}\left(w_{L}, w_{F_{1}}, w_{F_{2}}\right)=p\left(w_{L}, w_{F_{1}}, w_{F_{2}}\right) w_{F_{1}}$

$r_{F_{2}}^{\text {sus }}\left(w_{L}, w_{F_{1}}, w_{F_{2}}\right)=p\left(w_{L}, w_{F_{1}}, w_{F_{2}}\right) w_{F_{2}}$

Leader's decision problem is to choose the level of sustainability initiatives $w_{L} \geq 0$ that maximizes her net benefit function given as:

$\Pi_{L}^{\text {sus }}\left(w_{L} \mid p_{L}\left(w_{L}, w_{F_{1}}, w_{F_{2}}\right)\right)=r_{L}^{\text {sus }}\left(w_{L}, w_{F_{1}}, w_{F_{2}}\right)-c_{L}^{\text {sus }}\left(w_{L}, w_{F_{1}}\right.$,

$\left.w_{F_{2}}\right)=\left[p_{L}\left(w_{L}, w_{F_{1}}, w_{F_{2}}\right)-d\right] w_{L}$

Then, each follower's decision problem is to choose the level of sustainability investment $w_{F_{i}}$ that maximizes her benefit function. Thus follower 1 and follower 2's objective functions can be written as:

$\Pi_{F_{1}}^{\text {sus }}\left(w_{F_{1}} \mid p\left(w_{L}, w_{F_{1}}, w_{F_{2}}\right)\right)=r_{F_{1}}^{\text {sus }}\left(w_{L}, w_{F_{1}}, w_{F_{2}}\right)-c_{F_{1}}^{\text {sus }}\left(w_{L}, w_{F_{1}}\right.$,

$\left.w_{F_{2}}\right)=\left[p_{F_{1}}\left(w_{L}, w_{F_{1}}, w_{F_{2}}\right)-d\right] w_{F_{1}}$

$\Pi_{F_{2}}^{\text {sus }}\left(w_{F_{2}} \mid p\left(w_{L}, w_{F_{1}}, w_{F_{2}}\right)\right)=r_{F_{2}}^{\text {sus }}\left(w_{L}, w_{F_{1}}, w_{F_{2}}\right)-c_{F_{2}}^{\text {sus }}\left(w_{L}, w_{F_{1}}\right.$,

$\left.w_{F_{2}}\right)=\left[p_{F_{2}}\left(w_{L}, w_{F_{1}}, w_{F_{2}}\right)-d\right] w_{F_{2}}$

\subsubsection{Follower 2's problem}

To solve for the backward induction outcome of this game, we first compute $w_{F_{2}}^{*}=R_{F_{2}}\left(w_{F_{1}}, w_{L}\right)$, the optimal reaction for follower 2 to any sustainability investments $w_{F_{1}}$ and $w_{L}$ of the follower 1 and the leader, respectively.

Follower 2 solves the following optimization problem (PF2) given $w_{F_{1}}$ and $w_{L}$ :

$$
\begin{gathered}
(\mathrm{PF} 2) \max _{w_{F_{2}} \geq 0} \Pi_{F_{2}}^{\text {sus }}\left(w_{F_{2}} \mid w_{F_{1}}, w_{L}\right)=\max _{w_{F_{2}} \geq 0} w_{F_{2}} \\
{\left[a-b\left(w_{F_{2}}+(\theta-\gamma)\left(w_{F_{1}}+w_{L}\right)\right)-d\right]} \\
=\max _{w_{F_{2}} \geq 0}\left[(a-d) w_{F_{2}}-b(\theta-\gamma)\left(w_{F_{1}}+w_{L}\right) w_{F_{2}}-b w_{F_{2}}^{2}\right]
\end{gathered}
$$

Since $\Pi_{F_{2}}^{s u s}\left(w_{F_{2}} \mid w_{F_{1}}, w_{L}\right)$ is strictly concave (see Appendix A) its maximizer can be written as:

$\hat{w}_{F_{2}}=\frac{1}{2}\left[\frac{a-d}{b}-(\theta-\gamma)\left(w_{F_{1}}+w_{L}\right)\right]$

Then the optimal solution $\mathrm{w}_{F_{2}}^{*}=R_{F_{2}}\left(w_{F_{1}}, w_{L}\right)$ to (PF2), is given as

$\mathrm{w}_{F_{2}}^{*}= \begin{cases}0 & \text { if } \hat{w}_{F_{2}} \leq 0 \\ \hat{w}_{F_{2}} & \text { if } \hat{w}_{F_{2}}>0\end{cases}$

Property 1. The optimal solution Follower 2's problem is given by $\mathrm{w}_{F_{2}}^{*}=\max \left\{0, \hat{w}_{F_{2}}\right\}$.

Proof. The proof follows easily from (12) and (PF2).

Next, we compute $\mathrm{w}_{F_{1}}^{*}=R_{F_{1}}\left(\mathrm{w}_{F_{2}}^{*}, w_{L}\right)$, the optimal reaction for follower 1 given the leader's sustainability level $w_{L}$.

\subsubsection{Follower 1 's problem}

Follower 1 solves the following optimization problem (PF1) given $w_{L}$ :

$$
\begin{aligned}
& (\mathrm{PF} 1) \max _{w_{F_{1}} \geq 0} \Pi_{F_{1}}^{\text {sus }}\left(w_{F_{1}} \mid \mathrm{w}_{F_{2}}^{*}, w_{L}\right) \\
& \quad=\max _{w_{F_{1}} \geq 0} w_{F_{1}}\left[a-b\left(w_{F_{1}}+(\theta-\gamma) w_{L}+\theta \mathrm{w}_{F_{2}}^{*}\right)-d\right]
\end{aligned}
$$

We consider two cases:

Case 1If. $\mathrm{w}_{F_{2}}^{*}=0$, then

$\max _{w_{F_{1}} \geq 0} \Pi_{F_{1}}^{s u s}\left(w_{F_{1}} \mid \mathrm{w}_{F_{2}}^{*}=0, w_{L}\right)=\left[a-d-b(\theta-\gamma) w_{L}\right] w_{F_{1}}-b w_{F_{1}}^{2}$

Since, $\Pi_{F_{1}}^{\text {sus }}\left(w_{F_{1}} \mid \mathrm{w}_{F_{2}}^{*}=0, w_{L}\right)$ is strictly concave for any given $w_{L}$ (see Appendix B) its maximizer $\bar{w}_{F_{1}}=R_{F_{1}}\left(\mathrm{w}_{F_{2}}^{*}=0, w_{L}\right)$ can be written as:

$\bar{w}_{F_{1}}=R_{F_{1}}\left(\mathrm{w}_{F_{2}}^{*}=0, w_{L}\right)=\frac{1}{2}\left[\frac{a-d}{b}-(\theta-\gamma) w_{L}\right]$

Case 2If $\mathrm{w}_{F_{2}}^{*}=\hat{w}_{F_{2}}$, then. 


$$
\begin{aligned}
\max _{w_{F_{1} \geq 0} \geq \Pi_{F_{1}}}\left(w_{F_{1}} \mid \mathrm{w}_{F_{2}}^{*}=\right. & \left.\hat{w}_{F_{2}}, w_{L}\right)=\left[\frac{(a-d)(2-\theta)}{2}-b w_{L}\right. \\
& \left.\frac{(\theta-\gamma)(2-\theta)}{2}\right] w_{F_{1}}-\frac{2-\theta(\theta-\gamma)}{2} b w_{F_{1}}^{2}
\end{aligned}
$$

Since, $\Pi_{F_{1}}^{\text {sus }}\left(w_{F_{1}} \mid \mathrm{w}_{F_{2}}^{*}=\hat{w}_{F_{2}}, w_{L}\right)$ is strictly concave for any given $w_{L}$ (see Appendix B) its maximizer $\hat{w}_{F_{1}}=R_{F_{1}}\left(\mathrm{w}_{F_{2}}^{*}=\hat{w}_{F_{2}}, w_{L}\right)$ can be written as:

$\hat{w}_{F_{1}}=R_{F_{1}}\left(\mathrm{w}_{F_{2}}^{*}=\hat{w}_{F_{2}}, w_{L}\right)=\frac{(2-\theta)}{2(2-\theta(\theta-\gamma))}\left[\frac{a-d}{b}-(\theta-\gamma) w_{L}\right]$

Plugging in (16a) into (11) we can rewrite the second followers reaction function

$\hat{w}_{F_{2}}=\frac{\left(a-d-b w_{L}(\theta-\gamma)\right)(4-(2+\theta)(\theta-\gamma))}{4 \mathrm{~b}(2-\theta(\theta-\gamma))}$

Remark 1. $0 \leq \frac{(2-\theta)}{(2-\theta(\theta-\gamma))} \leq 1$ for any $\theta$ and $\gamma$ in $[0,1]$.

Remark 2. Based on Remark 1, if $\left(\frac{a-d}{b}-(\theta-\gamma) w_{L}\right)>0$ then $\bar{w}_{F_{1}}>\hat{w}_{F_{1}}>0$

Remark 3. Based on Remark 1, if $\left(\frac{a-d}{b}-(\theta-\gamma) w_{L}\right) \leq 0$ then $\bar{w}_{F_{1}} \leq \hat{w}_{F_{1}} \leq 0$

Based on Remarks 2 and 3, Property 2 below gives the values for. $\mathrm{w}_{F_{1}}^{*}=R_{F_{1}}\left(\mathrm{w}_{F_{2}}^{*}, w_{L}\right)$

Property 2. Let $\tilde{w}=\frac{a-d}{b}-(\theta-\gamma) w_{L}$. The optimal solution, $\mathrm{w}_{F_{1}}^{*}$, to $\max _{w_{F_{1}} \geq 0} \prod_{F_{1}}^{\text {sus }}\left(w_{F_{1}} \mid \mathrm{w}_{F_{2}}^{*}, w_{L}\right)$ is given in Table 2:

Proof See Appendix C.

Corollary 1. Based on Property 1 and Property 2, the optimal investments for follower 1 and follower 2 are

$\mathrm{w}_{F_{1}}^{*}=\hat{w}_{F_{1}}, \mathrm{w}_{F_{2}}^{*}=\hat{w}_{F_{2}}$ if $\frac{a-d}{b}-(\theta-\gamma) w_{L}>0$

$\mathrm{w}_{F_{1}}^{*}=0, \mathrm{w}_{F_{2}}^{*}=0$ if $\frac{a-d}{b}-(\theta-\gamma) w_{L} \leq 0$

Proof. See Appendix D.

\subsubsection{Leader's problem}

Next, we consider the leader's decision problem to choose the level of sustainability initiatives $w_{L} \geq 0$ that maximizes her net benefit function.

$\Pi^{L}\left(w_{L} \mid w_{F_{1}}, w_{F_{2}}\right)=r\left(w_{L}\right)-c\left(w_{L}\right) \cdot w_{L}$

$$
=w_{L}\left[a-b\left(w_{L}+\theta\left(w_{F_{1}}+w_{F_{2}}\right)\right)-d\right]
$$

Since the leader can solve the followers' problems as well as the followers, the leader should anticipate that the sustainability level choice $w_{L}$ will be met with the cumulative reaction of followers $\sum_{i=1}^{N-1} R_{F_{i}}\left(\sum_{j \neq i}^{N-1} w_{F_{j}} \mid w_{L}\right)$. For the one leader two followers case the leader solves:

$$
\begin{aligned}
& (\mathrm{PL}) \max _{w_{L} \geq 0} \Pi_{F_{L}}^{\text {sus }}\left(w_{L} \mid w_{F_{1}}, w_{F_{2}}\right) \\
& =\max _{w_{L} \geq 0} w_{L}\left(a-b\left(w_{L}+\theta\left(\mathrm{w}_{F_{1}}^{*}+\mathrm{w}_{F_{2}}^{*}\right)\right)-d\right)
\end{aligned}
$$

Based on Corrollary 1, we consider two cases:

Case 1. If $\mathrm{w}_{F_{1}}^{*}=0, \mathrm{w}_{F_{2}}^{*}=0$, then

$\Pi_{L}^{\text {sus }}\left(w_{L} \mid \mathrm{w}_{F_{1}}^{*}=0, \mathrm{w}_{F_{2}}^{*}=0\right)=\left[a-b w_{L}-d\right] w_{L}=(a-d) w_{L}-b w_{L}^{2}$

Since $\Pi_{L}^{s u s}\left(w_{L} \mid \mathrm{w}_{F_{1}}^{*}=0, \mathrm{w}_{F_{2}}^{*}=0\right)$ is strictly concave for any given $\gamma, \theta$, and $b$ (see Appendix E), its maximizer, $\bar{w}_{L}$, can be written as:

$\bar{w}_{L}=\frac{a-d}{2 b}$

Case 2. If $\mathrm{w}_{F_{1}}^{*}=\hat{w}_{F_{1}}, \mathrm{w}_{F_{2}}^{*}=\hat{w}_{F_{2}}$, then $\Pi_{L}^{s u s}\left(w_{L} \mid \mathrm{w}_{F_{1}}^{*}=\hat{w}_{F_{1}}, \mathrm{w}_{F_{2}}^{*}=\hat{w}_{F_{2}}\right)$

$=$

$w_{L}$

$\left(a-b\left(w_{L}+\theta\left(\frac{(2-\theta)\left((a-d)-w_{L} b(\theta-\gamma)\right)}{2 b(2-\theta(\theta-\gamma))}+\frac{\left(a-d-b w_{L}(\theta-\gamma)\right)(4-(2+\theta)(\theta-\gamma))}{4 \mathrm{~b}(2-\theta(\theta-\gamma))}\right)\right.\right.$

)$-d)$

$=w_{L}\left(a-d-b\left[w_{L}+\theta\left[\frac{\left(a-d-b w_{L}(\theta-\gamma)\right)(8+\gamma(2+\theta)-\theta(4+\theta))}{4 b(2-\theta(\theta-\gamma))}\right]\right]\right)$

Since $\Pi_{L}^{\text {sus }}\left(w_{L} \mid \mathrm{w}_{F_{1}}^{*}=\hat{w}_{F_{1}}, \mathrm{w}_{F_{2}}^{*}=\hat{w}_{F_{2}}\right)$ is strictly concave for any given $\gamma, \theta$, and $b$ (see Appendix E), its maximizer, $\hat{w}_{L}$, can be written as:

$\hat{w}_{L}=\frac{(a-d)\left(\theta\left(-8+4 \theta+\theta^{2}-\gamma(2+\theta)\right)+4[2-\theta[-\gamma+\theta]]\right)}{2 b\left(\theta\left(\gamma^{2}(2+\theta)-2 \gamma\left(-4+3 \theta+\theta^{2}\right)+\theta\left(-8+4 \theta+\theta^{2}\right)\right)\right.}$

$+4[2-\theta[-\gamma+\theta]])$

Property 3. The optimal solution to $\max _{w_{L} \geq 0} \Pi_{F_{L}}^{\text {sus }}\left(w_{L} \mid w_{F_{1}}, w_{F_{2}}\right)$ is given as $\mathrm{w}_{L}^{*}$

$$
\left\{\begin{array}{c}
\operatorname{argmax}\left\{\Pi_{L}^{\text {sus }}\left(\frac{a-d}{b(\theta-\gamma)} \mid \mathrm{w}_{F_{1}}^{*}=0, \mathrm{w}_{F_{2}}^{*}=0\right), \Pi_{L}^{\text {sus }}\left(\hat{w}_{L}\right.\right. \\
\left.\left.\mid \mathrm{w}_{F_{1}}^{*}=\hat{w}_{F_{1}}, \mathrm{w}_{F_{2}}^{*}=\hat{w}_{F_{2}}\right)\right\}, \text { if } \theta>\gamma \\
\max \left\{0, \hat{w}_{L}\right\}, \\
\text { if } \theta<\gamma
\end{array}\right.
$$

Proof. See Appendix F.

Corollary 2. Based on Corollary 1 and Property 3, there exist following 2 unique Stackelberg equilibrium outcomes as given in Table 3.

Proof. Proof follows easily from the proofs of Corollary 1 and Property 3.

Table 2

Optimal solution for Follower 1.

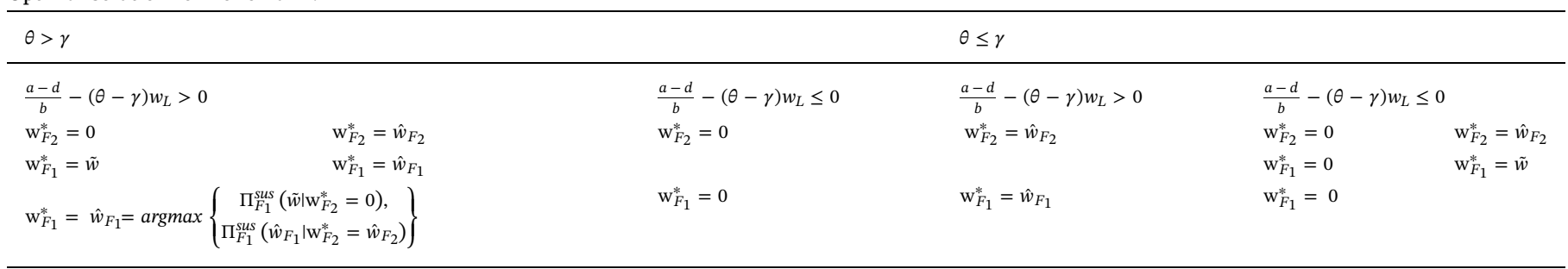


Table 3

Optimal solution for Leader.

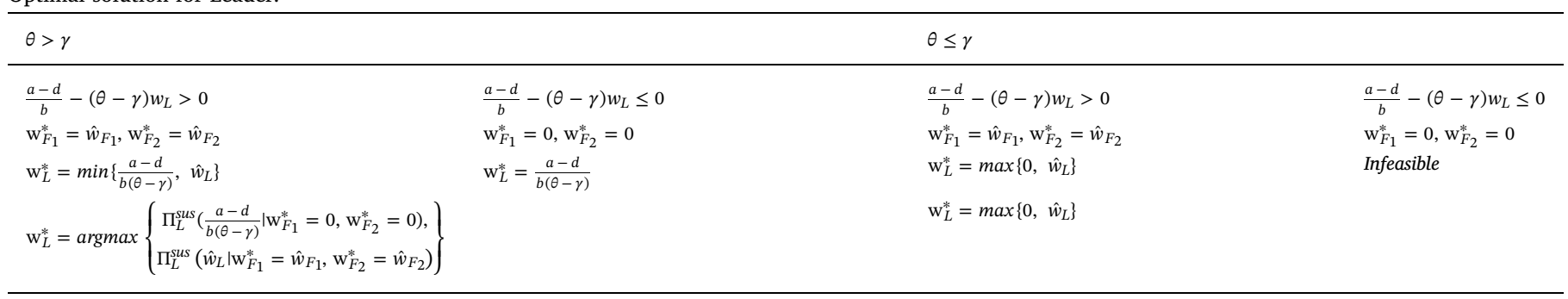

\section{Analysis and results}

\subsection{The effect of competition and spillover on the sustainability investments and net benefits of companies}

To gain better insight into the model's outcomes, we present graphical representations for the results in Corollary 2. Note that these results show the equilibrium conditions for the modeled Stackelberg game. We consider the sustainability investments and net benefits of companies in different markets where.

i) all firms only innovate $(\gamma=0)$ versus markets where follower firms imitate the leader and one another $(0 \leq \gamma \leq 1)$,

ii) sustainability offerings are substitutable $(0<\theta \leq 1)$ versus markets where sustainability offerings are not substitutable i.e. markets are separated $(\theta=0)$,

iii) changes in stakeholder payments have a relatively large effect on the demand for sustainability i.e. demand is elastic $(b=0.7<1)$ versus changes in stakeholder payments have a relatively small effect on the demand for sustainability i.e. demand is inelastic $(b=1.4>1)$.

We show the sustainability investments and net benefits of the leader and followers for $\mathrm{a}=1$, and $\mathrm{d}=0.6^{2}$ as competition $(0<\theta \leq 1)$ and spillover $(0<\gamma \leq 1)$ values change over their respective domains. The first result that emerges is that we can observe the same pattern for elastic and inelastic demand and same conclusions can be drawn regarding the effect of demand elasticity on the investment behavior of the players. Therefore, we discuss the likely reasons of the investment behavior for elastic demand $(b=0.7)$.

Using (11), (16) and (20), for $\gamma=0$ and $\theta=0$, we get $w_{L}=\frac{(a-d)}{2 b}$ and $w_{F_{1}}=w_{F_{2}}=\frac{(a-d)}{2 b}$. If there are no sustainability spillovers and the sustainability offerings are not substitutable i.e. the markets are separated; the leaders and the followers' sustainability investments are the same amount. For cases where $\gamma>0$ and $\theta>0$, the following results can be observed. For a given spillover rate, when the competition rate is higher than the spillover rate the leader's investments decrease as the competition rate increases. As seen in Fig. 2 (on the left graph), in markets where mostly all firms have to innovate in order to reap abnormal returns from sustainability, the leader makes the highest investment as soon as the competition rate exceeds (even slightly) the spillover rate and then decreases her investments as competition rate increases more, while the followers choose not to invest in sustainability.

In the opposite case as shown in Fig. 2 (on the right graph), in markets where follower firms mostly imitate the leader and one another and the competition rate is lower than the spillover rate the leader's investments are much smaller and show a similar pattern i.e. they

\footnotetext{
${ }^{2}$ We use $a=1, d=0.6$ and choose not to report results of different parameter constellations in terms of a and d, since $a$ and $d$ appear as a coefficient of $(a-d)$ in sustainability investment and net benefit functions and do not yield different results.
}

decrease as competition rate increases for a given spillover rate e.g. $\gamma=1$. Even though follower 1 and follower 2 have more incentives to invest in sustainability compared to the leader, they decrease their sustainability investments as competition rate increases as well.

For a given competition rate e.g. $\theta=1$, when the competition rate is higher than the spillover rate the leader's investments increase as the spillover rate increases up to the point when competition and spillover rates are equal. A seen in Fig. 3 (on the left graph), when the sustainability offerings are substitutable, the leader increases her investments and makes the highest investment when competition rate exceeds (slightly) the spillover rate. This result is rather counter intuitive. As spill over rate increases, we would expect the leader to decrease her sustainability investments in order to prevent the followers from free riding. However, when the effect of competition exceeds the effect of spillovers, the followers choose not to invest in sustainability, while the leader invests and increases her investments even though spillovers increase. The only plausible explanation is that the spillovers only occur in the form of improved stakeholder perception toward the whole market, which leads to market expansion. In this case, the leader would increase her sustainability investments despite the increasing spillover rate, since she would aim to cover the whole market, which expanded due to spillovers in the first place.

When the sustainability offerings are not substitutable, and the competition rate is lower than the spillover rate $(\theta<\gamma)$, the leader's investments are much smaller and show the reverse pattern i.e. they decrease as spillover rate increases for a given competition rate. As seen in Fig. 3 (on the right graph), when the effect of spillovers exceeds the effect of competition as the spillover rate increases, the leader decreases her sustainability initiatives and attempts to prevent the first and second followers from free riding the sustainability efforts, while the followers increase their sustainability investments. We can infer that when the effect of spillover exceeds the effect of competition, the spillovers also occur in the form of decreased initial implementation costs.

In Fig. 4 we observe the investment levels of all players as $\theta$ and $\gamma$ changes simultaneously. For $\theta>\gamma$ only the leader invests in sustainability, while the followers do not make any sustainability investments. The sustainability investments of the leader are affected negatively by the competition level. The leader's sustainability investments increase with increasing spillover rates, since the leader aims to reap all abnormal profits caused by the market expansion due to improved stakeholder perception towards the industry. For $\theta=\gamma$ all players invest in sustainability. Compared to $\theta<\gamma$ case we observe an abrupt decrease in the sustainability investments of the leader. As the competition level and spillover rate increase sustainability investments of the leader and first follower decrease, while the second follower's investments remain the same. Compared to $\theta>\gamma$ case the followers attain the minimum amount of investment.

For $\theta<\gamma$ all players invest in sustainability. As competition increases all players are discouraged to invest in sustainability. As spillover rates increase the leader is compelled to decrease her sustainability level to prevent the followers from free riding her sustainability efforts, while the followers invest more in sustainability to benefit from 

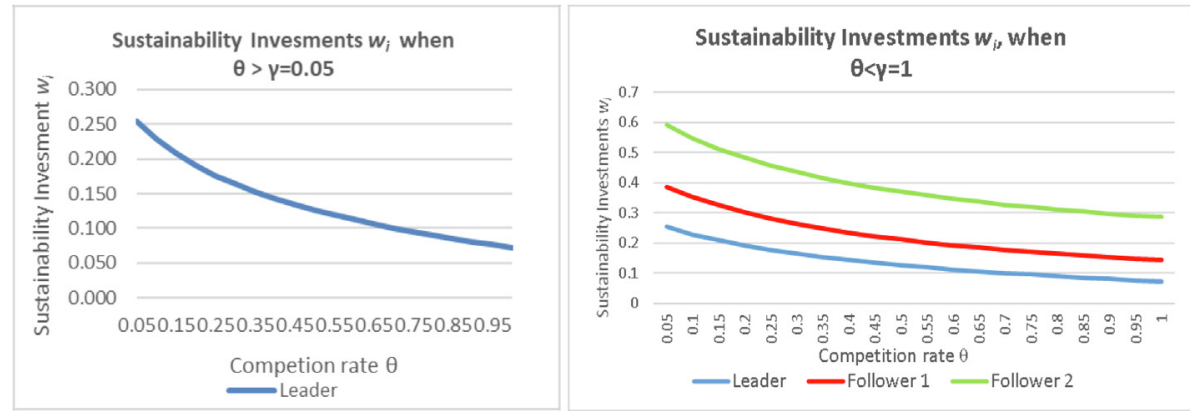

Fig. 2. The influence of competition on the sustainability investments for a given spillover rate.

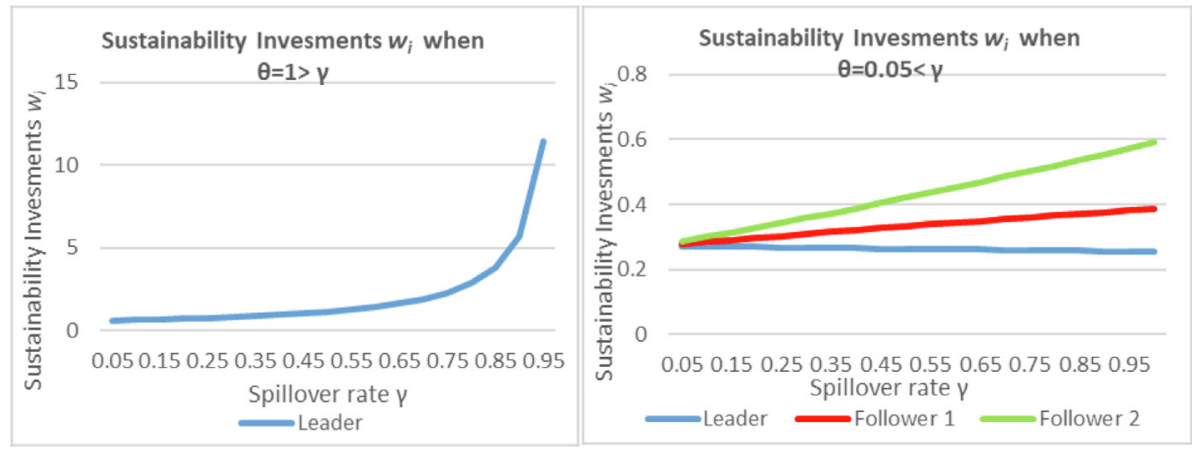

Fig. 3. The influence of spillovers on the sustainability investments for a given competition level.

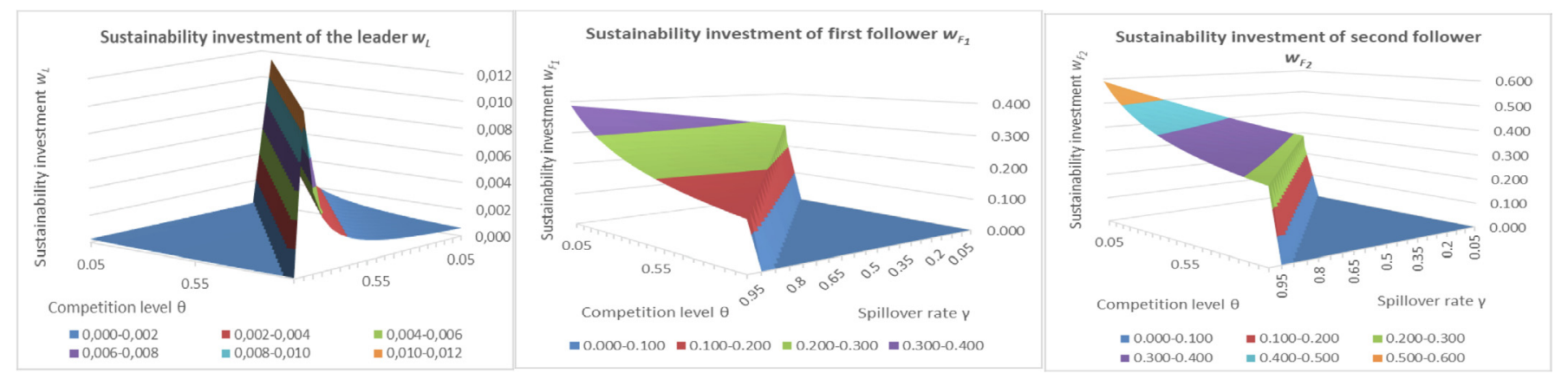

Fig. 4. The influence of competition level and spillovers rates on the sustainability investments.

accumulating spillovers and reap the abnormal profits. Compared to $\theta=\gamma$ case we observe gradual decrease in the sustainability investments of the leader and gradual increase for the followers.

Next, we identify the conditions under which, the leader, the first follower or the second follower invest in sustainability the most and attain advantage in terms of net benefits, under elastic and inelastic demand scenarios. In Fig. 5, the blue region represents the conditions under which the leader invests the most and attains the first mover advantage. We show only the case for $b=0.7$ since the results are similar for $b=1.7$. The green region represents the conditions under which follower 2 invests the most and attains the second mover advantage. For $\theta>\gamma$ the leader invests more than both her competitors

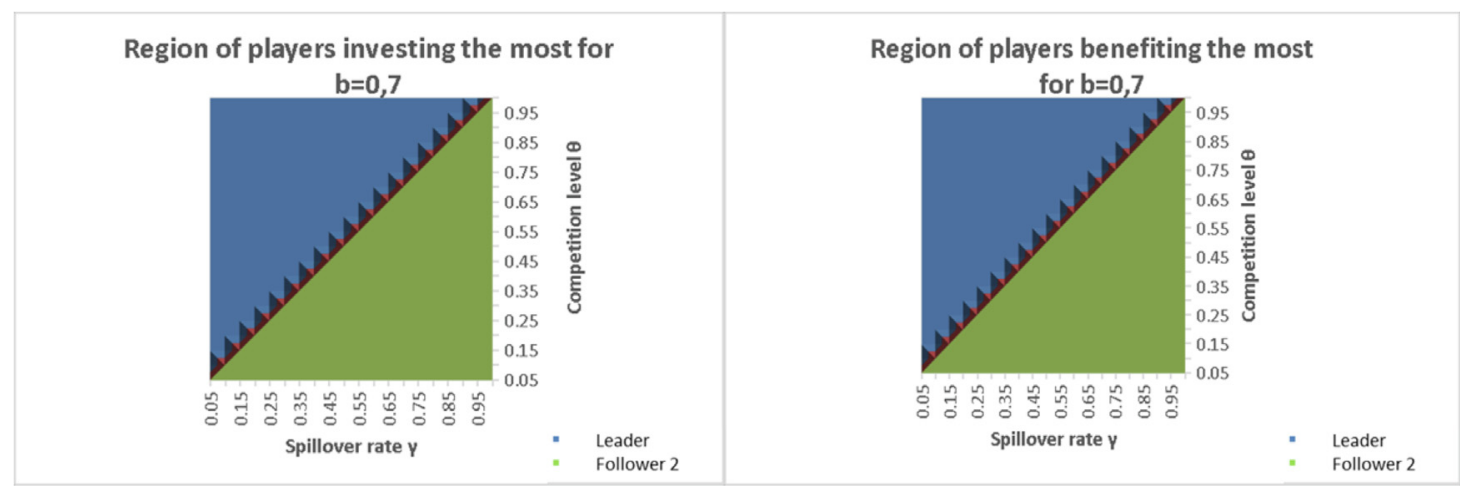

Fig. 5. The effect of competition and spillover on players, which invest in sustainability. the most and benefit the most. 
and benefits the most. For $\theta \leq \gamma$ the second follower invests more than the leader and first follower and benefits the most. These findings indicate that the first follower has the least incentive to invest in sustainability. The leader attains first mover advantage for low spillover rates and moderate to high competition levels. However, the leader is not able to retain her first mover advantage as the spillover rate increases and the advantage passes to the second follower. For both the elastic and inelastic demand cases as the competition level increases, the spillover rate at which the advantage passes from the leader to the second follower increases. Thus, for higher competition levels the first mover advantage is more defendable. These findings indicate that the first follower has the least incentive to invest in sustainability.

According to diffusion research ${ }^{3}$ innovation adopters are classified by time-of-adoption (Rogers, 2003, pp. 283): namely: (1) innovator (2) early adopter, (3) early majority, (4) late majority, and (5) laggards. The innovator introduces the innovation in to the market and launches the movement. The early adopter triggers the critical mass when they adopt an innovation. The early majority adopt the new innovation only after they observe that early adopters benefit from the new innovation. Thus, if the early adopter does not respond to innovator's action by taking a similar action, no one else joins the movement and the movement dies out.

The same may apply in the sustainability context. The first follower (early majority in the diffusion research context) has a role almost as important as the leader (early adopter in the diffusion research context) to spread the sustainability movement. If the first follower does not invest into sustainability, the second follower (late majority in the diffusion research context) will not adopt sustainability initiatives and sustainability dissemination may become highly unlikely.

If the goal of policy makers is to disseminate sustainability throughout an industry and transform the industry, they should give additional incentives to the first followers, since they are at disadvantage in terms of financial return as our results suggest and their adoption of sustainability is critical for sustainability dissemination. Moving forward we address the effect of competition and sustainability spillovers on the sustainability interactions from the policy makers view.

\subsection{The effect of competition and spillover over the total market outcome}

We also consider the effect of competition and sustainability spillovers over on the total market outcome. As seen in Fig. 6 (part 1), as the competition level increases the total market output for sustainability decreases. The total sustainability investments for elastic and inelastic demand have the same pattern and differ only in magnitude. Moreover, as spillover rate increases the total market output for sustainability increases. The total market sustainability outcome for elastic and inelastic demand differ in magnitude; the outcome for the elastic demand case is greater than the outcome for the inelastic demand case. Likewise, as seen in Fig. 6 (part 2), the cumulative net benefits of the companies decrease as the level of competition increases. This decrease is more prominent if spillover effect exists. As spillover rate increases the total net benefits of the market increases as well. The total net benefits for elastic and inelastic demand differ in magnitude; the net benefit of the total market for the elastic demand case is greater than the net benefit of the total market for the inelastic demand case.

In most circumstances, increasing price which leads to producer surplus does not compensate the reduction in consumer surplus. Thus, welfare is lowest if the market price equals the monopoly price and

\footnotetext{
3 "The diffusion of innovations is the process by which a few members of a social system initially adopt an innovation, then over time more individuals adopt until all (or most) members adopt the new idea." (Ryan and Gross, 1943) "An individual engages in a behavior based on the proportion of people in the social system already engaged in the behavior." (Granovetter, 1978).
}

highest if it equals the marginal cost of production. Increase competition is more likely to have a positive impact on total welfare (Motta, 2004). In the sustainability interactions model the stakeholder payment decreases as competition level increases. On the one hand, decreasing stakeholder payments cause reduction in producer surplus, which manifests itself as decreasing total net benefit. On the other hand, decreasing stakeholder payment cause increase in consumer surplus. If the goal of policy makers is to improve economic welfare, they should promote competition.

Increase in competition level causes decrease in sustainability investments of the total market. Since the total sustainability outcome of the market has a positive impact on social and environmental welfare, the decrease in total sustainability outcome has negative implications. If the goal of policy makers is to promote economic, social and environmental welfare simultaneously, they should regulate competition or subsidize companies by tax reduction and compensate the negative influence of competition on the total sustainability outcome of the market.

For the policy maker the spillovers are positive, since they increase the total market output and total net benefits regarding sustainability initiatives. Thus, policy makers should incentivize sustainability initiatives that transform the market rather than sustainability initiatives, which are company specific and hard to imitate.

\section{Conclusion}

We use a game-theoretic framework to understand the interrelated dynamics of sustainability actions of companies. We approach sustainability as a market that is shaped by the investments and strategic interactions of companies under the assumption of complete information. We propose a sequential model where, in the first stage the leader chooses her sustainability level by anticipating the cumulative response of multiple followers. In the succeeding stages the followers observe the sustainability investments of the leader and the cumulative sustainability outcome of their predecessor followers and choose their sustainability investments by anticipating the successor followers' cumulative sustainability levels. Using backward induction, we solve the 1 leader- 2 followers game and find the unique equilibrium solutions for different ranges of the competition levels and the spillover rates. Using a numerical example, we visualize the effect of competition and spillover on the sustainability initiatives, net benefits, and total sustainability outcomes of the market. We identify the conditions, when the first mover advantage, second mover advantage or last mover advantage arises.

The analytical model suggests that the leader has the first mover advantage for $\theta>\gamma$ and the first mover advantage becomes more defendable as the competition increases. For $\theta \leq \gamma$ the second follower benefits more than the leader. This result is in line with prior empirical research: A leader's sustainability activity is generally lower than her followers' sustainability activities (Hofer et al., 2012), since the leaders are less competitively aggressive, they implement simpler repertoires of actions and realize competitive actions more slowly (Ferrier et al., 1999).

Moreover, the analytical model suggests that either the first mover or the late adopter benefit the most. The first mover receives the whole stakeholder payment in the sustainability market, since her competitors have not yet invested in sustainability. The late adopter has an advantage, since she benefits from cumulative spillovers-increased net benefits due to market expansion caused by improved stakeholder perception of the whole industry and decreased implementation costs. The intermediate adopter fails to follow a clear strategy and cannot gain advantage over her competitors.

Albeit the first follower has the least motivation to invest in sustainability, she has a crucial role to play in sustainability dissemination. Thus, the policy makers should incentivize the first follower to invest in sustainability. To shed some light on the outcome of sustainability 


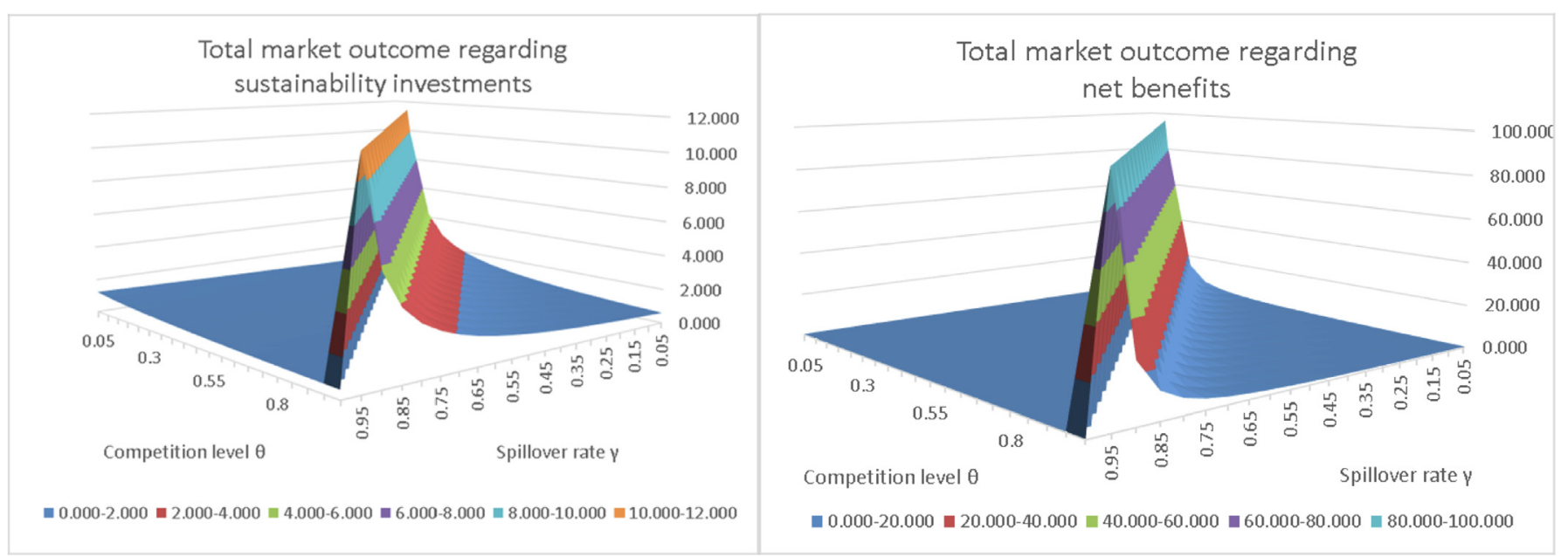

Fig. 6. The effect of competition and spillover on total market outcome regarding sustainability investments and net benefits.

interactions from the policy makers' point of view, we also studied the total market outcome for sustainability. Both the sustainability investment and net benefit of the total market for elastic demand are greater in magnitude than the sustainability investment and net benefit of the total market for inelastic demand. Furthermore, increasing competition levels decrease the total sustainability investments as well as the total benefits of the market, whereas, increasing spillover rates increase the total sustainability investments as well as the total benefits of the market. This result leads to the following policy implication for the social planner: Incentives should be provided for the sustainability initiatives that transform the total market, rather than sustainability initiatives, which are company specific and hard to imitate.

Future research questions arise such as the decomposition of latent profits into revenue and costs components, which would provide better understanding how strategic interactions influence the sustainability actions.

\section{Declarations of interest}

None.

\section{Acknowlegdement}

The authors thank Dr. Dincer Konur for his constructive inputs in an earlier version of this paper.

\section{Appendix}

A. Concavity of $\Pi_{F_{2}}^{\text {sus }}\left(\boldsymbol{w}_{F_{2}} \mid \boldsymbol{w}_{F_{1}}, \boldsymbol{w}_{L}\right)$

$\frac{\partial \Pi_{F_{2}}^{\text {sus }}\left(w_{F_{2}} \mid w_{F_{1}}, w_{L}\right)}{\partial w_{F_{2}}}=\left[a-d-b(\theta-\gamma)\left(w_{F_{1}}+w_{L}\right)\right]-2 b w_{F_{2}}$

$\frac{\partial^{2} \Pi_{F_{2}}^{s u s}\left(w_{F_{2}} \mid w_{F_{1}}, w_{L}\right)}{\partial w_{F_{2}}^{2}}=-2 b<0$ since $b>0$.

Thus $\Pi_{F_{2}}^{\text {sus }}\left(w_{F_{2}} \mid w_{F_{1}}, w_{L}\right)$ is strictly concave for any given $w_{L}$ and $w_{F_{1}}$.

B. Concavity of $\Pi_{1}^{\text {sus }}\left(\boldsymbol{w}_{F_{1}} \mid \mathbf{w}_{F_{2}}^{*}=0, w_{L}\right)$

$$
\begin{gathered}
\frac{\partial \Pi_{1}^{\text {sus }}\left(w_{F_{1}} \mid \mathrm{w}_{F_{2}}^{*}=0, w_{L}\right)}{\partial w_{F_{1}}}=\left[a-d-b(\theta-\gamma) w_{L}\right]-2 b w_{F_{1}} \\
\frac{\partial^{2} \Pi_{F_{1}}^{\text {sus }}\left(w_{F_{1}} \mid \mathrm{w}_{F_{2}}^{*}=0, w_{L}\right)}{\partial w_{F_{1}}{ }^{2}}=-2 b<0 \text { since. } b>0 \\
\text { Concavity of } \Pi_{1}^{\text {sus }}\left(w_{F_{1}} \mid \mathrm{w}_{F_{2}}^{*}=\hat{w}_{F_{2}}, w_{L}\right)
\end{gathered}
$$

$\frac{\partial \Pi_{1}^{\text {sus }}\left(w_{F_{1}} \mid \mathrm{w}_{F_{2}}^{*}=\hat{w}_{F_{2}}, w_{L}\right)}{\partial w_{F_{1}}}=\left[\frac{(a-d)(2-\theta)}{2}-b w_{L} \frac{(\theta-\gamma)(2-\theta)}{2}\right]-(2-\theta(\theta-\gamma)) b w_{F_{1}}$

$\frac{\partial^{2} \Pi_{F_{1}}^{\text {sus }}\left(w_{F_{1}} \mid w_{F_{2}}^{*}=\hat{w}_{F_{2}}, w_{L}\right)}{\partial w_{F_{1}}{ }^{2}}=-(2-\theta(\theta-\gamma)) b$

Note that when $\theta \geq \gamma, 0 \leq \theta-\gamma \leq 1$ since $\theta$ and $\gamma$ are both in $[0,1]$ and since $\mathrm{b}>0$ by definition, $-(2-\theta(\theta-\gamma)) b<0$. Similarly, when $\theta<\gamma$, $-1<\theta-\gamma \leq 0$ since $\theta$ and $\gamma$ are both in $[0,1]$ and since $\mathrm{b}>0$ by definition, $-(2-\theta(\theta-\gamma)) b<0$. Thus $\Pi_{F_{1}}^{\text {sus }}\left(w_{F_{1}} \mid \mathrm{w}_{F_{2}}^{*}=\hat{w}_{F_{2}}, w_{L}\right)$ is strictly concave for any given $w_{L}$.

C. Proof of Property 2.

We consider two cases for Follower 1. 
Case C1. We first consider Follower 1's problem when $\mathrm{w}_{F_{2}}^{*}=0$.

(PF1.1)

$\max _{w_{F_{1}} \geq 0} \Pi_{F_{1}}^{\text {sus }}\left(w_{F_{1}} \mid \mathrm{w}_{F_{2}}^{*}=0, w_{L}\right)=\max _{w_{F_{1}} \geq 0} w_{F_{1}}\left[a-b\left(w_{F_{1}}+(\theta-\gamma) w_{L}\right)-d\right]$

Recall from Property 1 that $\mathrm{w}_{F_{2}}^{*}=0$ when $\hat{w}_{F_{2}} \leq 0$. From the definition of $\hat{w}_{F_{2}}$, if $\hat{w}_{F_{2}} \leq 0$, then

$\frac{a-d}{b}-(\theta-\gamma) w_{L} \leq(\theta-\gamma) w_{F_{1}}$

Also, the maximizer of the function in (PF1.1) is $\bar{w}_{F_{1}}=\frac{1}{2}\left[\frac{a-d}{b}-(\theta-\gamma) w_{L}\right]$ (see (14)).

Case C1.1. $(\theta-\gamma)>0$

Divide both sides of (C1) by $(\theta-\gamma)$ and define $\tilde{w}$ as follows:

$\tilde{w}=\frac{1}{(\theta-\gamma)}\left[\frac{a-d}{b}-(\theta-\gamma) w_{L}\right] \leq w_{F_{1}}$

i) Suppose that $\left(\frac{a-d}{b}-(\theta-\gamma) w_{L}\right)>0$. Then $\tilde{w}>0$. Based on Remark 2 and the definitions of $\bar{w}_{F_{1}}$ and $\tilde{w}$ we have,

$\tilde{w}>\bar{w}_{F_{1}}>0$

Due to (C2) and (C3), $\bar{w}_{F_{1}}$ is not feasible to Follower 1's problem in this case. Due to concavity the optimal solution must then be on the boundry. Hence, $w_{F_{1}}=\tilde{w}$ solves Follower 1's problem (PF1.1) in this case.

ii) Suppose that $\left(\frac{a-d}{b}-(\theta-\gamma) w_{L}\right) \leq 0$. Then $\tilde{w}<0$. Based on Remark 3 and the definitions of $\bar{w}_{F_{1}}$ and $\tilde{w}$ we have,

$\tilde{w}<\bar{w}_{F_{1}}<0$

Due to (C2) and (C3), $\bar{w}_{F_{1}}$ is not feasible to Follower 1's problem in this case. Due to the concavity the optimal solution must then be on the boundry. Hence, $w_{F_{1}}=0$ solves Follower 1's problem (PF1.1) in this case.

Case C1.2. $(\theta-\gamma) \leq 0$

Divide both sides of (C1) by $(\theta-\gamma)$ and define $\tilde{w}$ as follows:

$\tilde{w}=\frac{1}{(\theta-\gamma)}\left[\frac{a-d}{b}-(\theta-\gamma) w_{L}\right] \geq w_{F_{1}}$

$\bar{w}_{F_{1}}>0>\tilde{w}$

i) Suppose that $\left(\frac{a-d}{b}-(\theta-\gamma) w_{L}\right)>0$. Then $\tilde{w}<0$. Based on Remark 2 and the definitions of $\bar{w}_{F_{1}}$ and $\tilde{w}$ we have,

Due to (C5) and (C6), Follower 1's problem is infeasible in this case.

Suppose that $\left(\frac{a-d}{b}-(\theta-\gamma) w_{L}\right) \leq 0$. Then $\tilde{w} \geq 0$. Based on Remark 3 and the definitions of $\bar{w}_{F_{1}}$ and $\tilde{w}$ we have,

$\bar{w}_{F_{1}} \leq 0 \leq \tilde{w}$

Due to (C5) and (C7), $\bar{w}_{F_{1}}$ is not feasible to Follower 1's problem in this case. Due to the concavity the optimal solution must then be on the boundry. Hence, $w_{F_{1}}=0$ solves Follower 1's problem (PF1.1) in this case.

Case C2. We now consider Follower 1's problem when $\mathrm{w}_{F_{2}}^{*}=\hat{w}_{F_{2}}$.

(PF1.2)

$\max _{w_{F_{1}} \geq 0} \Pi_{F_{1}}^{s u s}\left(w_{F_{1}} \mid w_{F_{2}}^{*}=\hat{w}_{F_{2}}, w_{L}\right)=\left[\frac{(a-d)(2-\theta)}{2}-b w_{L} \frac{(\theta-\gamma)(2-\theta)}{2}\right] w_{F_{1}}-\frac{2-\theta(\theta-\gamma)}{2} b w_{F_{1}}^{2}$

Recall from Property 1 that $\mathrm{w}_{F_{2}}^{*}=\hat{w}_{F_{2}}$ when $\hat{w}_{F_{2}}>0$. From the definition of $\hat{w}_{F_{2}}$, if $\hat{w}_{F_{2}}>0$, then

$\frac{a-d}{b}-(\theta-\gamma) w_{L}>(\theta-\gamma) w_{F_{1}}$

Also, the maximizer of the function in (PF1.2) is $\hat{w}_{F_{1}}=\frac{(2-\theta)}{2(2-\theta(\theta-\gamma))}\left[\frac{a-d}{b}-(\theta-\gamma) w_{L}\right]($ see (16)).

Case C2.1. $(\theta-\gamma)>0$

Divide both sides of (C8) by $(\theta-\gamma)$ and define $\tilde{w}$ as follows:

$\tilde{w}=\frac{1}{(\theta-\gamma)}\left[\frac{a-d}{b}-(\theta-\gamma) w_{L}\right]>w_{F_{1}}$

i) Suppose that $\left(\frac{a-d}{b}-(\theta-\gamma) w_{L}\right)>0$. Then $\tilde{w}>0$. Based on Remark 2 and the definitions of $\hat{w}_{F_{1}}$ and $\tilde{w}$ we have,

$\tilde{w}>\hat{w}_{F_{1}}>0$

Due to (C9) and (C10), $\hat{w}_{F_{1}}$ is feasible and $w_{F_{1}}=\hat{w}_{F_{1}}$ solves Follower 1's problem (PF1.2) in this case.

ii) Suppose that $\left(\frac{a-d}{b}-(\theta-\gamma) w_{L}\right) \leq 0$. Then $\tilde{w}<0$. Based on Remark 3 and the definitions of $\hat{w}_{F_{1}}$ and $\tilde{w}$ we have,

$\tilde{w}<\hat{w}_{F_{1}} \leq 0$ 
Due to (C9) and (C11), Follower 1's problem is infeasible in this case.

Case C2.2. $(\theta-\gamma) \leq 0$

Divide both sides of (C8) by $(\theta-\gamma)$ and define $\tilde{w}$ as follows:

$\tilde{w}=\frac{1}{(\theta-\gamma)}\left[\frac{a-d}{b}-(\theta-\gamma) w_{L}\right]<w_{F_{1}}$

i) Suppose that $\left(\frac{a-d}{b}-(\theta-\gamma) w_{L}\right)>0$. Then $\tilde{w}<0$. Based on Remark 2 and the definitions of $\hat{w}_{F_{1}}$ and $\tilde{w}$ we have,

$\hat{w}_{F_{1}}>0>\tilde{w}$

Due to (C12) and (C13), is feasible and $w_{F_{1}}=\hat{w}_{F_{1}}$ solves Follower 1's problem (PF1.2) in this case.

ii) Suppose that $\left(\frac{a-d}{b}-(\theta-\gamma) w_{L}\right) \leq 0$. Then $\tilde{w} \geq 0$. Based on Remark 3 and the definitions of $\hat{w}_{F_{1}}$ and $\tilde{w}$ we have,

$\hat{w}_{F_{1}} \leq 0 \leq \tilde{w}$

Due to (C12) and (C14), $\hat{w}_{F_{1}}$ is not feasible to Follower 1's problem in this case. Due to the concavity the optimal solution must then be on the boundry. Hence, $w_{F_{1}}=\tilde{w} \geq 0$ solves Follower 1's problem (PF1.2) in this case.

Note that $\Pi_{F_{1}}^{\text {sus }}\left(0 \mid \mathrm{w}_{F_{2}}^{*}=\hat{w}_{F_{2}}\right) \geq \Pi_{F_{1}}^{\text {sus }}\left(\tilde{w} \mid \mathrm{w}_{F_{2}}^{*}=\hat{w}_{F_{2}}\right)$ and $\Pi_{F_{1}}^{\text {sus }}\left(0 \mid \mathrm{w}_{F_{2}}^{*}=\hat{w}_{F_{2}}\right)=0$. Thus $\Pi_{F_{1}}^{\text {sus }}\left(\tilde{w} \mid \mathrm{w}_{F_{2}}^{*}=\hat{w}_{F_{2}}\right) \leq 0$ and. $w_{F_{1}}=0$.

D. Proof of Corollary 1

Suppose that $\left(\frac{a-d}{b}-(\theta-\gamma) w_{L}\right)>0$. Then, from Case C 1.1.(i), $\max _{F_{1} \geq 0} \Pi_{F_{1}}^{\text {sus }}\left(w_{F_{1}} \mid \mathrm{w}_{F_{2}}^{*}=0, w_{L}\right)=\tilde{w}$

and from Case C 2.1.(i), $\max _{w_{F_{1}} \geq 0} \Pi_{F_{1}}^{\text {sus }}\left(w_{F_{1}} \mid \mathrm{w}_{F_{2}}^{*}=0, w_{L}\right)=\hat{w}_{F_{1}}$. Therefore,

$\mathrm{w}_{F_{1}}^{*}=\operatorname{argmax}\left\{\Pi_{F_{1}}^{\text {sus }}\left(\tilde{w} \mid \mathrm{w}_{F_{2}}^{*}=0\right), \Pi_{F_{1}}^{\text {sus }}\left(\hat{w}_{F_{1}} \mid \mathrm{w}_{F_{2}}^{*}=\hat{w}_{F_{2}}\right)\right\}$

It can be seen by simple comparison that $\Pi_{F_{1}}^{\text {sus }}\left(\hat{w}_{F_{1}} \mid \mathrm{w}_{F_{2}}^{*}=\hat{w}_{F_{2}}\right)>\Pi_{F_{1}}^{\text {sus }}\left(\tilde{w} \mid \mathrm{w}_{F_{2}}^{*}=0\right)$, and therefore

$\mathrm{w}_{F_{1}}^{*}=\hat{w}_{F_{1}}, \mathrm{w}_{F_{2}}^{*}=\hat{w}_{F_{2}}$ if $\frac{a-d}{b}-(\theta-\gamma) w_{L}>0$

Suppose that $\left(\frac{a-d}{b}-(\theta-\gamma) w_{L}\right) \leq 0$. Then, from Case C 1.2.(ii), $\mathrm{w}_{F_{1}}^{*}=0$ and from Case 2.2.(ii) $\mathrm{w}_{F_{1}}^{*}=0$. Thus,

$\mathrm{w}_{F_{1}}^{*}=0, \mathrm{w}_{F_{2}}^{*}=0$ if $\frac{a-d}{b}-(\theta-\gamma) w_{L} \leq 0$

E. Concavity of $\Pi_{L}^{\text {sus }}\left(\boldsymbol{w}_{L} \mid \mathbf{w}_{F_{1}}^{*}=0, \mathbf{w}_{F_{2}}^{*}=0\right)$

$\frac{\partial \Pi_{L}^{s u s}\left(w_{L} \mid \mathrm{w}_{F_{1}}^{*}=0, \mathrm{w}_{F_{2}}^{*}=0\right)}{\partial w_{L}}=\left[a-d-b(\theta-\gamma) w_{L}\right]-2 b w_{F_{1}}$

$\frac{\partial^{2} \Pi_{L}^{s u s}\left(w_{L} \mid w_{F_{1}}^{*}=0, w_{F_{2}}^{*}=0\right)}{\partial w_{L}{ }^{2}}=-2 b<0$ since. $b>0$

Thus $\Pi_{L}^{\text {sus }}\left(w_{L} \mid \mathrm{w}_{F_{1}}^{*}=0, \mathrm{w}_{F_{2}}^{*}=0\right)$ is strictly concave.

Concavity of $\Pi_{L}^{\text {sus }}\left(\boldsymbol{w}_{L} \mid \mathbf{w}_{F_{1}}^{*}=\hat{\boldsymbol{w}}_{F_{1}}, \mathbf{w}_{F_{2}}^{*}=\hat{\boldsymbol{w}}_{F_{2}}\right)$.

$\frac{\partial \Pi_{L}^{\text {sus }}\left(w_{L} \mid \mathrm{w}_{F_{1}}^{*}=\hat{w}_{F_{1}}, \mathrm{w}_{F_{2}}^{*}=\hat{w}_{F_{2}}\right)}{\partial w_{L}}=(a-d)\left[1-\theta \frac{2(2-\theta)+(4-(2+\theta)(\theta-\gamma))}{4(2-\theta(\theta-\gamma))}\right]-2 b w_{L}\left[1-\theta(\theta-\gamma) \frac{2(2-\theta)+(4-(2+\theta)(\theta-\gamma))}{4(2-\theta(\theta-\gamma))}\right]$

$\frac{\partial^{2} \Pi_{L}^{\text {sus }}\left(w_{L} \mid \mathrm{w}_{F_{1}}^{*}=\hat{w}_{F_{1}}, \mathrm{w}_{F_{2}}^{*}=\hat{w}_{F_{2}}\right)}{\partial w_{L}{ }^{2}}=-2 b\left[1-\theta(\theta-\gamma)\left[\frac{2(2-\theta)+(4-(2+\theta)(\theta-\gamma))}{4(2-\theta(\theta-\gamma))}\right]\right]$

When $\theta \geq \gamma$,

$\theta-\gamma \geq 0$ and $-\gamma \leq 1$ since $\theta$ and $\gamma$ are both in [0,1], and since. $b>02(2-\theta)+(4-(2+\theta)(\theta-\gamma))>0$ and $4(2-\theta(\theta-\gamma))>0$

$\theta(\theta-\gamma) \frac{2(2-\theta)+(4-(2+\theta)(\theta-\gamma))}{4(2-\theta(\theta-\gamma))}>0$

if $1-\theta(\theta-\gamma) \frac{2(2-\theta)-(\theta+2)(\theta-\gamma)+4}{4(2-\theta(\theta-\gamma))}>0$

Then. $-2 b\left(\left(1-\theta(\theta-\gamma) \frac{2(2-\theta)+(4-(2+\theta)(\theta-\gamma))}{4(2-\theta(\theta-\gamma))}\right)<0\right.$

Since the expression in (E1) is at least a second order polynomial of $\theta$ and since $\theta$ and $\gamma$ are both in [0,1], the expression in (E2) is true.

Thus. $-2 b\left(\left(1-\theta(\theta-\gamma) \frac{2(2-\theta)+(4-(2+\theta)(\theta-\gamma))}{4(2-\theta(\theta-\gamma))}\right)<0\right.$

When. $\quad \theta \leq \gamma, \theta-\gamma \leq 0$ and $\theta-\gamma>-1$ since $\theta$ and $\gamma$ are both in $[0,1], 2(2-\theta)+(4-(2+\theta)(\theta-\gamma))>0$ and. $\quad 4(2-\theta(\theta-\gamma))>0$ $\theta(\theta-\gamma) \frac{2(2-\theta)+(4-(2+\theta)(\theta-\gamma))}{4(2-\theta(\theta-\gamma))}<0$ and. $1-\theta(\theta-\gamma) \frac{2(2-\theta)+(4-(2+\theta)(\theta-\gamma))}{4(2-\theta(\theta-\gamma))}>0$ and since $\mathrm{b}>0$

Thus. $-2 b\left(1-\theta(\theta-\gamma) \frac{2(2-\theta)-(\theta+2)(\theta-\gamma)+4}{4(2-\theta(\theta-\gamma))}\right)<0$.

Thus $\Pi_{L}^{\text {sus }}\left(w_{L} \mid \mathrm{w}_{F_{1}}^{*}=\hat{w}_{F_{1}}, \mathrm{w}_{F_{2}}^{*}=\hat{w}_{F_{2}}\right)$ is strictly concave for any given $\gamma, \theta$, and $b$. 
F. Proof of Property 3

We consider two cases for the leader.

Case F.1. Suppose that $\theta>\gamma$. Then, when.

$\frac{a-d}{b}-(\theta-\gamma) w_{L} \leq 0$, we have, $w_{L} \geq \frac{a-d}{b(\theta-\gamma)}$

and when.

$\frac{a-d}{b}-(\theta-\gamma) w_{L}>0$, we have, $w_{L}<\frac{a-d}{b(\theta-\gamma)}$

Also note that $\frac{a-d}{b(\theta-\gamma)}>0$ when $\theta>\gamma$.

Based on Property 2, Leader's subproblems become:

\section{Case F1.1.}

$\max \Pi_{L}^{\text {sus }}\left(w_{L} \geq 0 \mid w_{F_{1}}^{*}=0, w_{F_{2}}^{*}=0\right)=\left[a-b w_{L}-d\right] w_{L}=(a-d) w_{L}-b w_{L}^{2}$

s.t. $\quad w_{L} \geq \frac{a-d}{b(\theta-\gamma)}$

Since the maximizer $0 \leq \bar{w}_{L}=\frac{a-d}{2 b} \leq \frac{a-d}{b(\theta-\gamma)}, \frac{a-d}{b(\theta-\gamma)}$ solves the leader's problem in this case.

\section{Case F1.2.}

$\max \Pi_{L}^{\text {sus }}\left(w_{L} \geq 0 \mid w_{F_{1}}^{*}=\hat{w}_{F_{1}}, w_{F_{2}}^{*}=\hat{w}_{F_{2}}\right)$

$=w_{L}\left(a-d-b\left[w_{L}+\theta\left[\frac{1}{2}\left[\frac{a-d}{b}-(\theta-\gamma) w_{L}\right]+\frac{(2-\theta)}{2 b(2-\theta(\theta-\gamma))}\left[\frac{a-d}{b}-(\theta-\gamma) w_{L}\right]\right]\right]\right)$

s.t. $w_{L} \leq \frac{a-d}{b(\theta-\gamma)}$

It can be shown that when $\theta>\gamma$, the maximizer.

$\hat{w}_{L}=\frac{(a-d)\left(\theta\left(-8+4 \theta+\theta^{2}-\gamma(2+\theta)\right)+4[2-\theta[-\gamma+\theta]]\right)}{2 b\left(\theta\left(\gamma^{2}(2+\theta)-2 \gamma\left(-4+3 \theta+\theta^{2}\right)+\theta\left(-8+4 \theta+\theta^{2}\right)\right)+4[2-\theta[-\gamma+\theta]]\right)}>0$.

Thus, $\min \left\{\frac{a-d}{b(\theta-\gamma)}, \hat{w}_{L}\right\}$ solves the leader's problem in this case.

Suppose. $0 \leq \frac{a-d}{b(\theta-\gamma)}<\hat{w}_{L}$

Then $w_{L}=\frac{a-d}{b(\theta-\gamma)}$ solves the leader's problem. $\max \Pi_{L}^{s u s}\left(w_{L} \mid w_{F_{1}}^{*}=\hat{w}_{F_{1}}, w_{F_{2}}^{*}=\hat{w}_{F_{2}}\right)$

Hence we need to compare

$\Pi_{L}^{\text {sus }}\left(w_{L}=\frac{a-d}{b(\theta-\gamma)} \mid w_{F_{1}}^{*}=0, w_{F_{2}}^{*}=0\right)$ and $\Pi_{L}^{\text {sus }}\left(w_{L}=\hat{w}_{L} \mid w_{F_{1}}^{*}=\hat{w}_{F_{1}}, w_{F_{2}}^{*}=\hat{w}_{F_{2}}\right)$

And since the former is greater than the latter, we have $\mathrm{w}_{L}^{*}=\frac{a-d}{b(\theta-\gamma)}$, in Case F.1.

Suppose. $0 \leq \hat{w}_{L}<\frac{a-d}{b(\theta-\gamma)}$

Then $w_{L}=\frac{a-d}{b(\theta-\gamma)}$ solves the leader's problem. $\max \Pi_{L}^{s u s}\left(w_{L} \mid w_{F_{1}}^{*}=\hat{w}_{F_{1}}, w_{F_{2}}^{*}=\hat{w}_{F_{2}}\right)$

Hence we need to compare

$\Pi_{L}^{\text {sus }}\left(w_{L}=\frac{a-d}{b(\theta-\gamma)} \mid w_{F_{1}}^{*}=0, w_{F_{2}}^{*}=0\right)$ and $\Pi_{L}^{\text {sus }}\left(w_{L}=\frac{a-d}{b(\theta-\gamma)} \mid w_{F_{1}}^{*}=\hat{w}_{F_{1}}, w_{F_{2}}^{*}=\hat{w}_{F_{2}}\right)$

Therefore, in Case F.1,

$\mathrm{w}_{L}^{*}=\operatorname{argmax}\left\{\Pi_{L}^{\text {sus }}\left(\frac{a-d}{b(\theta-\gamma)} \mid \mathrm{w}_{F_{1}}^{*}=0, \mathrm{w}_{F_{2}}^{*}=0\right), \Pi_{L}^{\text {sus }}\left(\hat{w}_{L} \mid \mathrm{w}_{F_{1}}^{*}=\hat{w}_{F_{1}}, \mathrm{w}_{F_{2}}^{*}=\hat{w}_{F_{2}}\right)\right\}$

Solves the leader's problem.

Case F.2. Suppose that $\theta \leq \gamma$. Then, when.

$\frac{a-d}{b}-(\theta-\gamma) w_{L} \leq 0$, we have, $w_{L} \leq \frac{a-d}{b(\theta-\gamma)}$

and when.

$\frac{a-d}{b}-(\theta-\gamma) w_{L}>0$, we have, $w_{L}>\frac{a-d}{b(\theta-\gamma)}$

Also note that $\frac{a-d}{b(\theta-\gamma)}<0$ when $\theta \leq \gamma$.

Based on Property 2, Leader's subproblems become:

Case F 2.1.

$\max \Pi_{L}^{s u s}\left(w_{L} \geq 0 \mid w_{F_{1}}^{*}=0, w_{F_{2}}^{*}=0\right)=\left[a-b w_{L}-d\right] w_{L}=(a-d) w_{L}-b w_{L}^{2}$

s.t. $\quad w_{L} \leq \frac{a-d}{b(\theta-\gamma)}$

Since the maximizer $\frac{a-d}{2 b(\theta-\gamma)}<0$, the leader's problem is infeasible in case F2.1. 
Case F 2.2.

$\max \Pi_{L}^{\text {sus }}\left(w_{L} \geq 0 \mid w_{F_{1}}^{*}=\hat{w}_{F_{1}}, w_{F_{2}}^{*}=\hat{w}_{F_{2}}\right)$
$=w_{L}\left(a-d-b\left[w_{L}+\theta\left[\frac{1}{2}\left[\frac{a-d}{b}-(\theta-\gamma) w_{L}\right]+\frac{(2-\theta)}{2 b(2-\theta(\theta-\gamma))}\left[\frac{a-d}{b}-(\theta-\gamma) w_{L}\right]\right]\right]\right)$

s.t. $\quad w_{L}>\frac{a-d}{b(\theta-\gamma)}$

In Case F.2.2. the leader's problem is solved by. $\max \left\{0, \hat{w}_{L}\right\}$

Therefore, in Case F.2, $\mathrm{w}_{L}^{*}=\max \left\{0, \hat{w}_{L}\right\}$, solves the leader's problem.

\section{References}

Battini, D., Persona, A., Sgarbossa, F., 2014. A sustainable EOQ model: theoretical formulation and applications. Int. J. Prod. Econ. 149, 145-153.

Berman, S.L., Wicks, A.C., Kotha, S., Jones, T.M., 1999. Does stakeholder orientation matter? The relationship between stakeholder management models and firm financial performance. Acad. Manag. J. 42 (5), 488-506.

Besley, T., Ghatak, M., 2007. Retailing public goods: the economics of corporate social responsibility. J. Public Econ. 91, 1645-1663.

Carroll, R.J., Primo, D.M., Richter, B.K., 2016. Using item response theory to improve measurment in strategic management research: An application to corporate respon sibility. Strat. Manag. J. 37, 66-85.

Conrad, K., 2005. Price competition and product differentiation when consumers care for the environment. Environ. Resour. Econ. 31, 1-19.

Cheng, S., Chan, C.W., Huang, G.H., 2003. An integrated multi-criteria decision analysis and inexact mixed integer linear programming approach for solid waste management. Eng. Appl. Artif. Intell. 16, 543-554.

Cheng, B., Ioannou, İ., Sefafeim, G., 2014. Corporate social responsibility and access to finance. Strat. Manag. J. 35, 1-23.

Cristmann, P., 2000. Effects of best practices of environmental management on cost advantage: the role of complementary assets. Acad. Manag. J. 43 (No. 4), 663-680.

Darnall, N., Henriques, I., Sadorsky, P., 2008. Do environmental management systems improve business performance in an international setting? J. Int. Manag. 14, 364-376.

Donaldson, T., Preston, L., 1995. Stakeholder theory of the corporation - concepts evidence and implications. Acad. Manag. Rev. 20 (1), 65-91.

Eccles, R.G., Ioannou, I., Serafeim, G., 2014. The impact of corporate sustainability on organizational processes and performance. Manag. Sci. 60 (1), 2835-2857.

Esenduran, G., Kemahlığlu-Ziya, E., Swaminathan, J.M., 2017. Impact of take-back regulation on the remanufacturing industry. Prod. Oper. Manag. 26 (5), 924-944.

Enkvist, P.A., Nauclér, T., Rosander, J., 2007. A cost curve for greenhouse gas reduction. McKinsey Q. 35-45.

Ferrier, W.J., Smith, K.G., Grimm, C., 1999. The role of competitive action in market share erosion and industry dethronement: a study of industry leaders and challengers. Acad. Manag. J. 42 (4), 372-388.

Galbreth, M., Ghosh, B., 2013. Competition and sustainability: the impact of consumer awareness. Decis. Sci. J. 44 (1), 127-159.

Golicic, S.L., Smith, C.D., 2013. A Meta-Analysis of environmentally sustainable supply chain management practices and firm performance,. J. Supply Chain Manag. 49 (2), 78-96.

Granovetter, M., 1978. Threshold models of collective behavior. Am. J. Sociol. 83, 1420-1443.

Grewatsch, S., Kleindienst, I., 2017. When does it pay to be good? Moderators and mediators in the corporate sustainability-corporate financial performance relationship: a critical review. J. Bus. Ethics 145, 383-416.

Hall, J., Wagner, M., 2012. Integrating sustainability into firms' processes: performance effects and the moderating role of business models and innovation. Bus. Strateg. Environ. 21, 183-196.

Hitchcock, D.E., Willard, M.L, 2009. The Business Guide to Sustainability: Practical Strategies and Tools for Organizations, second ed. Routledge, London, pp. 59-78.

Hofer, C., Cantor, D.E., Dai, J., 2012. The competitive determinants of a firm's environmental management activities: evidence from US manufacturing industries. J. Oper. Manag. 30, 69-84.

Huck, S., Muller, W., Normann, H.T., 2001. Stackelberg beats Cournot: on collusion and efficiency in experimental markets. Econ. J. 111 (474), 749-765.

Jacobs, B.W., Subramanian, R., 2012. Sharing responsibility for product recovery across the supply chain. Prod. Oper. Manag. 21 (1), 85-100.

Jørgensen, S., 2010. A dynamic game of waste management. J. Econ. Dyn. Control 34 $258-265$.

Karmperis, A.C., Aravossis, K., Tatsiopoulos, I.P., Sotirchos, A., 2013. Decision support models for solid waste management: review and game-theoretic approaches Waste Management. 33, 1290-1301.

Kopel, M., 2009. Strategic CSR, Spillovers, and First-Mover Advantage. Available at SSRN: https://ssrn.com/abstract $=1408632$ or https://doi.org/10.2139/ssrn. 1408632, Accessed date: 28 May 2018

Kopel, M., Lamantia, F., Szidarovszky, F., 2014. Evolutionary competition in a mixed market with socially concerned firms. J. Econ. Dyn. Control 48, 394-409.

Lambertini, L., Tampieri, A., 2015. Incentives, performance and desirability of socially responsible firms in a Cournot oligopoly. Econ. Modell. 50, 40-48.

Lee, D., 2012. Turning waste into by-product. Manuf. Serv. Oper. Manag. 14 (1) 115-127.

Leoneti, A.B., Pires, E.C., 2017. Decision sciences in the management of water resources: multi-criteria methods and game theory applied to the field of sanitation. J. Water,
Sanit. Hyg. Dev. 7 (2), 229-242.

Li, Y., Richardson, G.D., Thornton, D.B., 1997. Corporate disclosure of environmental liability information: theory and evidence. Contemp. Account. Res. 14 (3), 435-474.

Liu, Z., Anderson, T.D., Cruz, J.M., 2012. Consumer environmental awareness and competition in two-stage supply chains. Eur. J. Oper. Res. 218, 602-613.

Majumder, P., Groenevelt, H., 2001. Competition in remanufacturing. Prod. Oper. Manag. 10 (2), 125-141.

Manasakis, C., Mitrokostas, E., Petrakis, E., 2014. Strategic corporate social responsibility activities and corporate governance in imperfectly competitive markets. Manag. Decis. Econ. 35, 460-473.

Mangala, S., Madaan, J., Chan, F.T.S., 2013. Analysis of flexible decision strategies for sustainability-focused green product recovery system. Int. J. Prod. Res. 51 (11) 3428-3442.

Margolis, J.D., Elfenbein, H.A., Walsh, J.P., 2009. Does it Pay to Be Good... and Does it Matter? A Meta-Analysis of the Relationship between Corporate Social and Financial Performance.

Matisoff, D., 2015. Sources of specification errors in the assessment of voluntary environmental programs: understanding program impacts. Pol. Sci. 48, 109-126.

McWilliams, A., Siegel, D.S., Wright, M., 2001. Corporate social responsibility: a theory from the firm perspective. Acad. Manag. Rev. 26 (1), 117-127.

McWilliams, A., Siegel, D.S., Wright, M., 2006. Corporate social responsibility: strategic implications. J. Manag. Stud. 43 (1), 1-18.

Mendoza, A.J., Clemen, R.T., 2013. Outsourcing sustainability: a game theoretic modeling approach. Environment Systems and Decisions 33, 224-236.

Moraga-González, J.L., Padrón-Fumero, N., 2002. The adverse effects of environmental policy in green markets. Environ. Resour. Econ. 22 (3), 419-447.

Moretti, S., 2004. A Model for Cooperative Inter-municipal Waste Collection: Cost Evaluation toward Fair Cost Allocation. [book auth.] C., Fragnelli, V. Carraro. Game Practice and the Environment: A Model for Cooperative Inter-municipal Waste Collection: Cost. s.L. Edward Elgar Publishing, pp. 125-144.

Motta, M., 2004. Competition Policy: Theory and Practice. Cambridge University Press, New York, USA, pp. 124

Orlitzky, M., Siegel, D.S., Waldman, D.A., 2011. Strategic corporate responsibility and environmental sustainability. Bus. Soc. 50 (1), 6-27.

Orsdemir, A., Kemahlıŏ̆lu-Ziya, E., Parlaktürk, A.K., 2014. Competitive quality choice and remanufacturing. Prod. Oper. Manag. 23 (1), 48-64.

Peloza, J., 2009. The challenge of measuring financial impacts from investments in corporate social performance. J. Manag. 35 (6), 1518-1541.

Piga, C., 2002. Corporate social responsibility: a theory of the firm perspective. A few comments and some suggestions. Acad. Manag. Rev. 27, 13-15.

Plambeck, E., Wang, Q., 2009. Effects of E-waste regulation on new product introduction. Manag. Sci. 55 (3), 333-347.

Preston, L.E., O'Bannon, D., 1997. The corporate social-financial performance relationship. Bus. Soc. 36 (4), 419-429.

Rodriguez-Ibeas, R., 2007. Environmental product differentiation and environmental awareness. Environ. Resour. Econ. 36, 237-254.

Rogers, E.M., 2003. Diffusion of Innovations, fifth ed. Free Press, New York, USA, pp. 283

Ruf, B.M., Muralidhar, K., Brown, R.M., Janney, J.J., Paul, K., 2001. An empirical investigation of the relationship between change in corporate social performance and financial performance: a stakeholder theory perspective. J. Bus. Ethics 32, 143-156.

Ryan, B., Gross, N., 1943. The diffusion of hyprid seed corn in two Iowa communities. Rural Sociol. 8, 15-24.

Sabbaghia, M., Behdadb, S., Zhuanga, J., 2016. Managing consumer behavior toward ontime return of the waste electrical and electronic equipment: a game theoretic approach. Int. J. Prod. Econ. 182, 545-563.

Schoenherr, T., 2012. The role of environmental management in sustainable business development: a multi-country investigation. Int. J. Prod. Econ. 140 (1), 116-128.

Schoenherr, T., Talluri, S., 2013. Environmental sustainability initiatives: a comparative analysis of plant efficiencies in europe and the U.S. Transactions on Engineering Management 60 (2), 353-365.

Sengupta, A., 2015. Competitive investment in clean technology and uninformed green consumers. J. Environ. Econ. Manag. 71, 125-141.

Soltani, A., Sadiq, R., Hewage, K., 2016. Selecting sustainable waste-to-energy technologies for municipal solid waste treatment: a game theory approach for group decision-making. J. Clean. Prod. 13, 388-399.

Unruh, G., 2010. Can You Compete on Sustainability?. Harvard Business Review. https:// hbr.org/2010/03/can-you-compete-on-sustainabil, Accessed date: 9 March 2018.

Unruh, G., Kiron, D., Kruschwitz, N., Reeves, M., Rubel, H., zum Felde, A.M., 2016. Investing for a Sustainable Future. MIT Sloan Management Review.

Wernerfelt, B., 1984. A resource- based view of the firm. Strat. Manag. J. 5 (2), 179-191.

Yadav, P.L., Han, S.H., Kim, H., 2017. Sustaining competitive advantage through corporate environmental performance. Bus. Strateg. Environ. 26, 345-357.

Xu, L., Wang, C., Li, H., 2017. Decision and coordination of low carbon supply chain considering technological spillover and environmental awareness. Sci. Rep. 7, 1-14. 